\title{
On the Pollutant Removal, Dispersion, and Entrainment over Two-Dimensional Idealized Street Canyons
}

\author{
Chun-Ho Liu and Colman C.C. Wong \\ Department of Mechanical Engineering, The University of Hong Kong, Hong Kong
}

\begin{abstract}
Pollutant dispersion over urban areas is not that well understood, in particular at the street canyon scale. This study is therefore conceived to examine how urban morphology modifies the pollutant removal, dispersion, and entrainment over urban areas. An idealized computational domain consisting of 12 two-dimensional (2D) identical street canyons of unity aspect ratio is employed. The large-eddy simulation (LES) is used to calculate the turbulent flows and pollutant transport in the urban boundary layer (UBL). An area source of uniform pollutant concentration is applied on the ground of the first street canyon. A close examination on the roof-level turbulence reveals patches of low-speed air masses in the streamwise flows and narrow high-speed downdrafts in the shear layer. Different from the flows over a smooth surface, the turbulence intensities are peaked near the top of the building roughness. The pollutant is rather uniformly distributed inside a street canyon but disperses quickly in the UBL over the buildings. Partitioning the vertical pollutant flux into its mean and turbulent components demystifies that the pollutant removal is mainly governed by turbulence. Whereas, mean wind carries pollutant into and out of a street canyon simul-
\end{abstract}


taneously. In addition to wind speed promotion, turbulent mixing is thus required to dilute the ground-level pollutants, which are then removed from the street canyon to the UBL. Atmospheric flows slow down rapidly after the leeward buildings, leading to updrafts carrying pollutants away from the street canyons (the basic pollutant removal mechanism).

Keywords: air quality, coherent structure, large-eddy simulation, pollutant plume dispersion, pollutant removal mechanism, urban boundary layer

\section{Introduction}

One of the most pronounced effects of human activities on micro-climate 3 and air chemistry/quality is in cities (Landsberg, 1970; Minoura, 1999; Tu 4 et al., 2007; Chang et al., 2009; Notario et al., 2012). Urban areas are the 5 sites consisting of most anthropogenic pollutant emission (Piringer et al., 6 2007; Kim Oanh et al., 2008; Chen et al., 2009) where the vast majority of 7 people live (United Nation, 2008). Yet, a greater population density could 8 promote more efficient energy consumption and hence lower down per capita 9 carbon footprint (Parrish and Zhu, 2009).

10 The scalar transport, such as heat, moisture, and pollutants, in the atmospheric boundary layer (ABL) is an attractive research topic with a range 2 of application. Turbulent transport over a variety of natural terrain has been well explored. For example, the transport of atmospheric constituents culated well by the Gaussian plume model (Pasquill, 1983). On the other hand, urban morphology imposes radical changes in radiative, thermodynamic, and aerodynamic characteristics at the ABL bottom. It hence influ- 
ences micro-climate, enhances turbulence, and modifies air pollutant mixing and transport (Mazzeo and Venegas, 1991; Baklanov, 2009), giving rise to the development of urban boundary layer (UBL). In the absence of any topography, buildings are the roughness elements of a city. The major flow characteristics in built areas result from building wakes, road intersections, and street canyon effects. Building wakes are largely due to the flows around an isolated building. Whereas, in building clusters, the wakes associated with individual buildings interact with each other resulting in the recirculating flows at the UBL bottom. Apparently, there is a knowledge gap in urban dispersion, in particular in the neighborhood scales with explicitly resolved buildings in which the most serious threats to urban inhabitants, including heavy vehicular exhaust and accidental toxic release, are posed.

Approaches to atmospheric transport in the UBL are broadly divided into field measurements (Roth, 2000), laboratory experiments (Ahmad et al., 2005), and mathematical modeling (Vardoulakis et al., 2003; Li et al., 2006) that complement each other. Focusing on a length scale in the range $1 \mathrm{~km}$ to $3.5 \mathrm{~km}$, Britter et al. (2002) compared the accuracy of steady-state and unsteady-state pollutant transport models. Rotach et al. (2005) conducted the Basel UrBan Boundary Layer Experiment (BUBBLE) to measure turbulence and tracer over urban, sub-urban, and rural areas. Using the same UBL scenario in New York City, Hanna et al. (2006) tested five computational fluid dynamics (CFD) models which agreed well with the observed wind flows during a field experiment. Recently, Dispersion of Air Pollution and its Penetration into the Local Environment (DAPPLE), which was a major campaign focusing on the effects of city architecture and prevail- 
ing climatic conditions in North European, was carried out in London to examine the pollutant mixing and transport in a complex and dense urban environment (Wood et al., 2009).

Although the models are necessarily simplified, a few field measurement campaigns using reduced-scale building blocks have been performed to test the sensitivity of UBL pollutant transport to building geometry and dimensions. Measuring the pollutant plume dispersion from the source in the first or second row over an array of cubes of size $2 \mathrm{~m}$, Davidson et al. (1995) found that the mean vertical plume extent increases by $40 \%$ to $50 \%$ compared with that over open and flat terrain. Employing another array consisting of over 100 rectangular blocks of size $1.10 \mathrm{~m} \times 1.10 \mathrm{~m} \times 1.15 \mathrm{~m}$ (length $\times$ width $\times$ height), Macdonald et al. (1998) investigated how the density of roughness elements affects the plume dispersion behind a ground-level point source. The horizontal plume coverage is about 2 to 4 times wider than that over an open and flat terrain. Using a series of reduced-scale field measurements, and wind tunnel and water channel experiments, Yee et al. (2006) consistently found that urban obstacles modify pollutant plume dispersion substantially in which the plume spread is promoted by a factor of 2 to 4 .

To test the sensitivity of pollutant dispersion to turbulence in a controllable manner, a number of laboratory experiments using wind tunnels or water channels have been carried out to examine pollutant transport in UBL. Meroney et al. (1996) implemented the technique using line sources to simulate the vehicular pollutant transport in street canyons. A street canyon is the basic unit constructing a city. An elucidation of its transport processes can enrich the fundamental understanding of pollutant removal in entire ur- 
ban areas. The flows over an isolated building and building clusters were found to exhibit different pollutant dispersion behaviors. Afterward, the spatial distributions of mean and root-mean-square (RMS) pollutant concentrations were measured by Pavageau and Schatzmann (1999) in details that has been serving as a major dataset for the validation of mathematical models. Earlier theoretical studies outlined the vertical profiles of (decreasing) pollutant concentration in a street canyon. Likewise, Kastner-Klein and Plate (1999) measured the pollutant concentration distributions on the leeward and windward facades that are in line with the vertical profiles of decreasing pollutant concentration as found in early theoretical studies. Louka et al. (2000) used field measurements to demonstrate the importance of intermittent recirculating flows to street-level ventilation. A series of sensitivity tests were performed by Chang and Meroney (2001) and Chang and Meroney (2003) to study how the dimensions of buildings and streets affect pollutant transport. Jiang et al. (2007) applied flow visualization in a water channel, illustrating the pollutant transport behaviors in step-up and step-down notch street canyons. The aforementioned field measurements and laboratory experiments lay down the foundation of urban structures for atmospheric dispersion in the UBL.

Similar to other turbulence researches, mathematical modeling has been playing a major role in probing the flows and pollutant transport in urban areas. Using large-eddy simulation (LES), Liu and Barth (2002) and Liu et al. (2005) studied the turbulent pollutant transport inside a street canyon, and compared the pollutant distribution in street canyons of aspect ratio $0.5,1$, and 2. Cui et al. (2004), focusing on the LES-calculated turbulence charac- 
teristics in and over a street canyon, attempted to determine the turbulence scales. Afterwards, the pollutant transport from a line source (vehicular pollutant) or an area source (heat transfer) was examined in Cai et al. (2008). Letzel et al. (2008) recently realized the functionality of Kelvin-Helmholtz instabilities related to urban pollutant dispersion formulating the hypothesis of the pollutant removal by turbulence rather than mean flows.

Although the pollutant dispersion in urban areas has been examined in numerous studies, for example, the use of quadrant analysis in Cheng and Liu (2011), a number of key questions remain unclear. In this paper, we attempt to use LES with coherent structures to address the mechanism of pollutant removal from two-dimensional (2D) idealized street canyons and the pollutant transport aloft in the UBL. Moreover, a detailed analysis on the turbulent flows is carried out to differentiate the role of mean wind and turbulence in pollutant removal and entrainment. This section outlines the problem background. The modeling details are described in Section 2. A comprehensive diagnosis is conducted in Section 3. Apart from the properties of flows and pollutant transport below the canopy level (Section 3.1) and in the UBL over the buildings (Section 3.2), a thorough analysis on the pollutant removal mechanism is performed in Section 3.3. Afterward, we look into the coherent structures of flow and pollutant transport in Section 3.4 to reveal their coupling. Finally, the conclusion is drawn in Section 4.

\section{Methodology}

\subsection{Governing Equations}

LES in the open-source CFD code OpenFOAM (2013) is used in this 
study. The flow is assumed to be isothermal and incompressible that consists of the continuity

$$
\frac{\partial \bar{u}_{i}}{\partial x_{i}}=0
$$

and the filtered Navier-Stokes equation, written as

$$
\frac{\partial \bar{u}_{i}}{\partial t}+\frac{\partial}{\partial x_{j}} \bar{u}_{i} \bar{u}_{j}=-\frac{\Delta \mathrm{P}}{\Delta x} \delta_{i 1}-\frac{\partial \bar{\pi}}{\partial x_{i}}-\frac{\partial \tau_{i j}}{\partial x_{j}}+\nu \frac{\partial^{2} \bar{u}_{i}}{\partial x_{j} \partial x_{j}}
$$

in modified form where $\bar{u}_{i}$ are the resolved-scale velocity components in the $i$-direction, $x_{i}$ the Cartesian coordinates, $\Delta \mathrm{P} / \Delta x$ the background kinematic pressure gradient, $\nu$ the kinematic viscosity, and $\delta_{i j}$ the Kronecker delta. The resolved-scale modified pressure $\bar{\pi}$ is defined as

$$
\bar{\pi}=\bar{p}+\frac{2}{3} k_{\mathrm{SGS}}
$$

where $\bar{p}$ is the resolved-scale kinematic pressure and $k_{\text {SGS }}$ the subgrid-scale (SGS) turbulent kinetic energy (TKE). The SGS Reynolds stresses $-\tau_{i j}$ are modeled in the form

$$
-\tau_{i j}=-\left(\overline{u_{i} u_{j}}-\bar{u}_{i} \bar{u}_{j}\right)=\nu_{\mathrm{SGS}}\left(\frac{\partial \bar{u}_{i}}{\partial x_{j}}+\frac{\partial \bar{u}_{j}}{\partial x_{i}}\right)+\frac{2}{3} k_{\mathrm{SGS}} \delta_{i j}
$$

using the Smagorinsky SGS model (Smagorinsky, 1963). Here, $\nu_{\mathrm{SGS}}(=$ $\left.\mathrm{C}_{k} k_{\mathrm{SGS}}^{1 / 2} \Delta\right)$ is the kinematic eddy viscosity, $\Delta\left(=\left[\Delta_{1} \Delta_{2} \Delta_{3}\right]^{1 / 3}\right)$ the filter width, and $\mathrm{C}_{k}(=0.07)$ the empirical modeling constant. The one-equation SGS model (Schumann, 1975)

$$
\frac{\partial k_{\mathrm{SGS}}}{\partial t}+\frac{\partial}{\partial x_{i}} k_{\mathrm{SGS}} \bar{u}_{i}=-\frac{1}{2} \tau_{i j} \frac{\partial \bar{u}_{i}}{\partial x_{j}}+\left(\nu+\nu_{\mathrm{SGS}}\right) \frac{\partial^{2} k_{\mathrm{SGS}}}{\partial x_{i} \partial x_{i}}-\mathrm{C}_{\epsilon} \frac{k_{\mathrm{SGS}}^{3 / 2}}{\Delta}
$$

is used to solve the SGS TKE conservation where $\mathrm{C}_{\epsilon}(=1.05)$ is another empirical modeling constant. This approach has been used in our previous studies of flows and pollutant transport over street canyons. 
The pollutant transport is calculated by the advection-diffusion equation of a passive and inert scalar

$$
\frac{\partial \bar{\phi}}{\partial t}+\frac{\partial}{\partial x_{i}} \bar{\phi} \bar{u}_{i}=-\frac{\partial \gamma_{i}}{\partial x_{i}}+\frac{\nu}{\operatorname{Sc}} \frac{\partial^{2} \bar{\phi}}{\partial x_{i} \partial x_{i}}
$$

where $\bar{\phi}$ is the resolved-scale pollutant concentration and Sc $(=0.72)$ the Schmidt number. The SGS pollutant flux is modeled in the form

$$
\gamma_{i}=\overline{\phi u_{i}}-\bar{\phi} \bar{u}_{i}=-\frac{\nu_{\mathrm{SGS}}}{\mathrm{Sc}} \frac{\partial \bar{\phi}}{\partial x_{i}}
$$

\subsection{Computational Domain and Boundary Conditions}

Different from some previous studies using cubes (Coceal et al., 2006; Kanda, 2006), the current LES computational domain (Fig. 1) is homogeneous in the spanwise direction that consists of 12 identical, idealized street canyons of height $h$ at the bottom and the UBL of depth $\mathrm{H}(=7 h)$ above the buildings. The buildings measure $d(=h)$ in length and $5 h$ in width that are evenly placed at a separation $b(=h)$ apart constructing street canyons of unity aspect ratio in this study.

The flow is driven by the background kinematic pressure gradient $\Delta \mathrm{P} / \Delta x$ in the UBL only that results in the prevailing wind speed $U$ at the domain top $z=\mathrm{H}$. The prevailing wind, whose direction is aligned by $\delta_{i 1}$ in Equation (2), is perpendicular to the street axis representing the worst scenario of urban pollutant removal. The boundary conditions (BCs) of the flow are periodic in the streamwise and spanwise directions. No-slip BCs, using a wall model (Spalding, 1962), are prescribed on all rigid walls. The implementation of wall model for flows over street canyons was detailed in Cheng and Liu (2011). Its major function is to ensure that the near-wall shear force is well balanced 
even if the surface sublayer is not resolved to fine resolution. A shear-free boundary is applied at the domain top. The aforementioned configuration represents fully developed turbulent flow in an open channel with a rough bottom surface.

The ground of the first street canyon right after the inflow boundary is a surface of constant concentration $\Phi$ serving the area pollutant source in the LES by the Dirichlet $\mathrm{BC} \bar{\phi}=\Phi$. The use of a constant-concentration BC also facilitates the interpretation of energy transport from a surface of constant temperature because of the analogy between heat and mass transfer. At the inflow, the concentration is zero so no background pollutant is considered. At the outflow, an open boundary for pollutant

$$
\frac{\partial \bar{\phi}}{\partial t}+\bar{u} \frac{\partial \bar{\phi}}{\partial x}=0
$$

is assumed hence the pollutant is carried away from the computational domain by the prevailing flow. Zero-gradient BCs of pollutant are applied along the domain top and the solid boundaries.

\subsection{Numerical Methods}

In the current LES, the implicit second-order accurate backward differencing is used in the temporal domain. The second-order accurate Gaussian finite volume integration scheme, which is based on the summation on cell faces, is adopted in the calculation of gradient, divergence, and Laplacian terms. The values on cell faces are interpolated by the central differencing of the values at centers. The gradient normal to a surface (used in the Laplacian terms) is calculated by the explicit non-orthogonal correction method. 
$32 \times 160 \times 32($ streamwise $\times$ spanwise $\times$ vertical $)$ and $768 \times 160 \times 280$ elements were discretized, respectively, in each street canyon and the UBL such that the total number of elements exceeds 34 million. The first element is placed at $z^{+} \approx 5$ away from the nearby solid boundary so that the spatial resolution is reasonably fine enough handling the near-wall flows. The LES is integrated for over 1,600 time steps and the time increment $\Delta t$ is $0.015 h / \mathrm{U}$. The Reynolds number based on the free-stream speed and the building height $\operatorname{Re}(=\mathrm{U} h / \nu)$ is 10,000 and the Reynolds number based on friction velocity $\operatorname{Re}_{\tau}\left(=u_{\tau} h / \nu\right)$ is 837 . The friction velocity $u_{\tau}\left(=\left[\tau_{w} / \rho\right]^{1 / 2}\right.$ where $\tau_{w}$ is the shear stress over the street canyons and $\rho$ the fluid density) is calculated by the force balance in the streamwise direction $u_{\tau}=(\Delta \mathrm{P} / \Delta x \times \mathrm{H})^{1 / 2}$. The shear stress profile is linear in the vertical direction. The numerical methodology is detailed elsewhere (Wong and Liu, 2010a,b).

\section{Results and Discussion}

In this paper, we focus on both below the canopy level and over the street canyons. The flows and pollutant transport are examined that are discussed in this section.

\subsection{Below the Roof Level}

\subsubsection{Flow Field}

Fig. 2 shows the vertical profiles of the ensemble average streamwise velocity $\langle\bar{u}\rangle$ on the 5 vertical planes of a street canyon $(x=0$ is the street center). Because the flows are cyclic in the streamwise direction, ensemble averaging is applied on the 12 identical street canyons which is represented 
by angular parentheses $\langle\bar{\psi}\rangle$. The characteristic velocity scale $\mathrm{U}_{\mathrm{s}}$ is the mean wind speed in the UBL within $h \leq z \leq 1.5 h$. A noticeable velocity gradient is developed along the roof level. It is steep on the leeward side (downwind side after a building) because of the flow separation at the leeward building edge. The gentle velocity gradient on the windward side (upwind side before a building) partly signifies the thorough turbulent mixing which entrains momentum into the street canyon. For a street canyon of unity aspect ratio in the skimming flow regime (Oke, 1988), the flow inside is shear driven moving toward the windward side in the upper part. The average wind speed in the street is about $10 \%$ of $\mathrm{U}_{\mathrm{s}}$, representing the rather weak downward momentum transport to the ground level.

Fig. 3 compares the vertical profiles of the ensemble average vertical velocity $\langle\bar{w}\rangle$. The upward flow on the leeward side carries aged air away from the street canyon. On the windward side, the downward flow entrains relatively cleaner air aloft to make up the aged air. Combining with the characteristic streamwise flow (Fig. 2), a clockwise recirculation occupying the entire street canyon is clearly depicted whose rotation speed is no more than $0.5 \mathrm{U}_{\mathrm{s}}$.

Fig. 4 shows the vertical profiles of the ensemble average resolved-scale $\operatorname{TKE}\left(=\left\langle u^{\prime \prime} u^{\prime \prime}+v^{\prime \prime} v^{\prime \prime}+w^{\prime \prime} w^{\prime \prime}\right\rangle / 2\right)$ in and over the street canyons. Here, double prime denotes the deviation of the variable from its ensemble average $\psi^{\prime \prime}$ $(=\bar{\psi}-\langle\bar{\psi}\rangle)$ and $\mathrm{TKE}_{\mathrm{s}}$ is the mean resolved-scale TKE in the UBL within $h \leq z \leq 1.5 h$. The large $\langle\mathrm{TKE}\rangle$ over the street canyon is attributed to the shear layer. On the contrary, the small and rather uniformly distributed $\langle\mathrm{TKE}\rangle$ inside the street canyon ( $10 \%$ to $20 \%$ of TKEs) is caused by the weak recirculating flows below the roof level. Wind shear is the only mechani- 
cal turbulence production in isothermal flows, the strong velocity gradient originated from the flow separation at the leeward building edge is hence the major source. The TKE is peaked on the windward roof level instead of coinciding with the maximum wind shear, suggesting the importance of advection redistributing TKE inside the street canyon. Vertical mixing continues as the flow moves from the leeward to windward sides and is reflected in the more gentle windward TKE gradient.

The coefficient of skewness

$$
s_{\psi}=\left\langle\psi^{\prime \prime 3}\right\rangle /\left\langle\psi^{\prime \prime} \psi^{\prime \prime}\right\rangle^{3 / 2}
$$

and the coefficient of kurtosis

$$
k_{\psi}=\left\langle\psi^{\prime \prime 4}\right\rangle /\left\langle\psi^{\prime \prime} \psi^{\prime \prime}\right\rangle^{2}
$$

are commonly used to measure, respectively, the degree of asymmetry and peakedness of turbulence signals. Coefficient of skewness measures the direction and degree of asymmetry of the probability density function (PDF). It equals 0 for a symmetric (normal) distribution. Positive values for the coefficient of skewness indicate a distribution that is weighted towards the positive direction and vice versa. Coefficient of kurtosis measures the degree of peaking or flatness of a distribution. It equals 3 for a normal distribution so the excess kurtosis $\left(=k_{\psi}-3\right)$ is often used instead. A positive value of the excess kurtosis indicates a peaked distribution compared with the normal distribution while negative a flat one.

The PDF of the streamwise turbulent velocity is symmetrical except near roof level where it becomes skewed in the shear layer, as is evidenced by the sharp-peak in $s_{u}$ (Fig. 5). The positive $s_{u}$ also signifies that the characteristic 
flow structures are comprised of patches of low-speed air mass and narrow high-speed air masses along the roof level. This finding is in line with the low-momentum fluid close to the plane of building roof observed in Michioka et al. (2011b). A narrow region of large $s_{u}$ is located in the area $-0.25 \leq$ $x / h \leq 0$, near roof level. The region spreads and descends somewhat in moving toward $x / h=0.4$ whilst the peak value significantly decreases. The PDF thus tends to return to a normal distribution most likely because of the enhanced turbulent mixing following the clockwise-rotating recirculation.

Similar to its skewness counterpart, the kurtosis of the streamwise velocity $k_{u}$ is peaked in $-0.25 \leq x / h \leq 0$ (Fig. 6). Hence, the patches of slow streamwise-moving air masses are most likely to be found on the leeward side. The profile of kurtosis of the streamwise velocity spreads out while moving toward the windward side, signifying the return to a flat PDF close to the normal distribution. The large positive kurtosis also shows that slowmoving air masses are more common on the leeward side.

Analogously, the skewness of the vertical velocity $s_{w}$ deviates from that of the normal distribution substantially along the roof level (Fig. 7). Owing to the strong shear, the broad peak of $s_{w}$ is negative, located just below the roof level, illustrating the dominance of roof-level updrafts and a few narrow high-speed downdrafts. The roof-level ensemble average vertical speed is close to zero because of the isolated recirculation in the skimming flow regime. The narrow downdrafts then govern the turbulence entrainment into the street canyons. Although the shear is weak near the windward wall, $s_{w}$ weights toward the negative direction in which the narrow downdrafts penetrate all the way down to the ground level. These large-scale, persistent 
downdrafts are likely caused by the vigorous wall jet carrying fresh air entrainment and turbulence along the windward facade. Similarly, $s_{w}$ leaned toward the positive direction near the leeward facade in which the narrow updrafts are initiated by the upward flows of the clockwise recirculation.

A mild peak of kurtosis of the vertical velocity $k_{w}$ is found right below the roof level (Fig. 8). Similar to other statistic properties, the $k_{w}$ peak descends in the streamwise direction following the primary clockwise recirculation. It is noteworthy that a broad peak of positive excess kurtosis is observed on the windward side at $x=0.4 b$. Hence, the strongest, narrow downdrafts are concentrated in the vicinity to the windward facade entraining turbulence and fresh air along with the wall jet down to the ground level.

Also shown in Figs. 2 to 8 are the wind tunnel measurements (Brown et al., 2000) and the LES results (Cui et al., 2004) available in literature. The profiles of streamwise (Fig. 2) and vertical (Fig. 3) velocity obtained from different studies agree well with each other. Whereas, the rotating speed of the (clockwise) recirculation in the street canyon obtained in Brown et al. (2000) is higher than that of Cui et al. (2004) and the current LES. Besides, the wind-tunnel measured TKE is higher than that of the two LESs. Turbulence is purposely produced by vortex generators to model the ABL in the wind tunnel. On the contrary, the LES turbulence is only generated mechanically by wind shear and Reynolds stresses. The flows and turbulence in the wind tunnel experiment are likely stronger than its LES counterparts.

The velocity skewness (Figs. 5 and 7) and kurtosis (Figs. 6 and 8) are also comparable with each other. In particular, the roof-level skewed flows are consistently revealed by the wind tunnel experiments and LESs. However, 
the skewness $s_{w}$ and kurtosis $k_{w}$ of the vertical velocity on the windward side show a little discrepancy among different studies that is likely caused by the abrupt entrainment from the prevailing flow.

While most studies have focused on the turbulence statistics inside or close to street canyons, we compare the current LES with our previous one (Cheng and Liu, 2011) in which a smaller spatial domain $(\mathrm{H}=6 h$ and three street canyons) was used to contrast the different UBL flow characteristics. As shown in Fig. 2, the ensemble average streamwise velocity calculated by the current LES is smaller than that reported in Cheng and Liu (2011). It could be a result of the shallower UBL (shorter vertical domain extent) or the flow was not fully developed in our previous study so the prevailing winds right over the buildings are accelerated. On the other hand, the ensemble average vertical velocity calculated by both LESs is almost zero due to the horizontal homogeneity (Fig. 3). Nevertheless, the differences in mean flows are small compared with those in turbulence statistics.

The TKE calculated by the two LESs is at the same level in the vicinity to the roof level, however, the value calculated by Cheng and Liu (2011) decreases sharply in the UBL core (Fig. 4). Apparently, this difference in TKE is a result of the no-slip top BCs adopted such that the TKE tends to diminish toward the upper domain boundary. In case the UBL is too shallow or remains developing, the constant shear layer is too thin that would underestimate the vertical transport right over the buildings. The uncertainties in TKE subsequently affect the skewness and kurtosis of velocity components. The streamwise (Fig. 5) and vertical (Fig. 7) velocities show, respectively, negative skewed and positive skewed peaks in the UBL at $z=4 h$. Whilst, 
the turbulence statistics should resume to normal distribution in the vertical direction because of the reducing shear stress in the UBL core. We believe that this discrepancy is caused by the diminishing TKE in the shallow UBL, over amplifying the skewness calculated by Cheng and Liu (2011). The above explanation also applies to the peaks of kurtosis above roof level calculated in our previous LES (Figs. 6 and 8).

\subsection{Over the Roof Level}

In the UBL over the buildings, the street canyons are treated as homogeneous urban roughness elements so the ensemble average flow properties $\left\langle\psi_{\text {flow }}\right\rangle$ are taken in both the streamwise $x$ and spanwise $y$ directions. On the other hand, the pollutant source is only assigned on the ground in the first street canyon, the ensemble average pollutant properties $\left\langle\psi_{\text {pollutant }}\right\rangle$ are taken in the spanwise direction only that are reported on the vertical $x-z$ plane.

\subsubsection{Flow Field}

A sensitivity test is performed to examine how the domain size affects the flows and the length scale of the eddies. The autocorrelation (Pope, 2009)

$$
R_{\psi \psi}\left(x_{0}, \delta x\right)=\frac{\left\langle\psi^{\prime \prime}\left(x_{0}\right) \psi^{\prime \prime}\left(x_{0}+\delta x\right)\right\rangle}{\left\langle\psi^{\prime \prime}\left(x_{0}\right) \psi^{\prime \prime}\left(x_{0}\right)\right\rangle}
$$

of the velocity components in the streamwise direction are depicted in Fig. 9. The decreasing trends of autocorrelation of the spanwise $R_{v v}$ and the vertical $R_{w w}$ velocities exhibit a similar pattern that diminishes rapidly within the current LES streamwise domain extent. However, the autocorrelation of the streamwise velocity $R_{u u}$ persists unless the elevation $z$ is lower than 1.7h. This finding is in line with our presumption that eddy size increases at a 
higher elevation. The faster decreasing $R_{\psi \psi}$ near the roof level is a result of the eddy size related to urban roughness. The size of the roof-level eddies is limited by the street width that is obviously smaller than that in the UBL and so is the integral length scale. Although the current LES domain size is larger than that of the direct numerical simulation (DNS) over an array of staggered cubes by Coceal et al. (2006) by $50 \%$, the LES-calculated $R_{u u}$ still persists around 0.1 that is only slightly lower than its DNS counterpart. The different building geometries in the DNS and the LES could be the major reason. The autocorrelation shows that the current LES domain is just large enough for the largest eddies. While our major concern is the near-roof region, it is adopted in this study.

Fig. 10 compares the profile of the current LES-calculated mean streamwise velocity $\langle\bar{u}\rangle$ with those of analytical solution and other numerical models in the UBL. It is observed that the LES is close to the $1 / 4$ power law and the log law $\left(u^{+}=1 / \kappa \times \ln z^{+}+5.5\right)$ instead of the analytical $1 / 7$ power law for flows over smooth surface (Douglas et al., 1995). The profile of Coceal et al. (2006) is slightly higher in the domain core, in which the difference is likely caused by the enhanced turbulent mixing in and over the staggered cubes. Cheng and Liu (2011) and the current study have used the same CFD LES code, whereas, the former shows a more uniform speed at the mid level of the domain in $0.2 \mathrm{H} \leq(z-h) \leq 0.8 \mathrm{H}$. The dissimilar domain size could be the major reason. Only 3 street canyons were used in Cheng and Liu (2011) while a much longer streamwise extent consisting of 12 street canyons are used in the current LES. The larger domain size can accommodate more large, energy-carrying eddies in the UBL that avoids development 
of effectively infinitely long eddies overpredicting the turbulent mixing.

The vertical profiles of RMS velocity $\left\langle u_{i}^{\prime \prime} u_{i}^{\prime \prime}\right\rangle^{1 / 2}$, which is the major driving force for turbulent mixing and transport, are illustrated in Fig. 11. Once $2 \mathrm{D}$ street canyons are introduced to the UBL bottom, the maximum RMS streamwise velocity $\left\langle u^{\prime \prime} u^{\prime \prime}\right\rangle^{1 / 2}$ shifts downward to the roof level because of the form drag, sharp velocity gradient, and locally elevated turbulence production. The streamwise RMS velocity $\left\langle u^{\prime \prime} u^{\prime \prime}\right\rangle^{1 / 2}$ decreases with increasing height that is a result of the gentler velocity gradient in the UBL core. The maximum spanwise RMS velocity $\left\langle v^{\prime \prime} v^{\prime \prime}\right\rangle^{1 / 2}$ elevates a little over the roof level. Finally, the vertical RMS velocity $\left\langle w^{\prime \prime} w^{\prime \prime}\right\rangle^{1 / 2}$ is peaked at $0.25 h$ over the roof level similar to that in Cheng and Liu (2011).

Also shown in Fig. 11 are the vertical profiles of RMS velocities in the turbulent boundary layer over various solid boundaries. Nagaosa (1999) considered the flows over a smooth surface at a Reynolds number, based on the channel depth, $\operatorname{Re}=2,300\left(\operatorname{Re}_{\tau}=150\right)$ using DNS. The maximum $\left\langle u_{i}^{\prime \prime} u_{i}^{\prime \prime}\right\rangle^{1 / 2}$ is located away from the wall that is in line with the characteristic in a turbulent boundary layer (Kim et al., 1987). Also using DNS, Ashrafian et al. (2004) studied the flows over 2D ribs of aspect ratio $1 / 8$ in the isolated roughness regime. The maximum RMS horizontal velocities are located at the roof level, while the maximum RMS vertical velocity is located at $z=$ $1.15 \mathrm{~h}$ that is higher than that of the current LES. Coceal et al. (2006) examined the flows over an array of staggered cubes using DNS. The maximum RMS streamwise velocity is also located at the roof level but the magnitude is slightly higher than that of the current LES over 2D street canyons. 


\subsubsection{Pollutant Transport}

Fig. 12 depicts the ensemble average pollutant concentration $\langle\bar{\phi}\rangle$ on the vertical $x-z$ plane. The UBL pollutant distribution generally resembles the Gaussian plume shape (Wong and Liu, 2010a,b). Except in the first street canyon with the ground-level pollutant source, the pollutant is quite well mixed and no noticeable variation of pollutant distribution is observed in the street canyons. A close examination on the tracer shows that the pollutant concentration decays in the vertical and likewise in the longitudinal direction having reached a local maximum (Fig. 13). Right at the roof level, the decreasing pollutant concentration exhibits different patterns over the building roofs and the street canyons. It is more uniform over the building roofs but is decreased more rapidly over the street canyons. This different pollutant dispersion behavior is mainly due to the enhanced pollutant mixing over the street canyons compared with that over buildings. Besides, the pollutant concentration gradient is steeper on the leeward side (than that on the windward side). It is a result of the clockwise recirculation which carries polluted air masses upward out of the street canyons along the leeward building facades.

Fig. 14 depicts the contours of RMS pollutant concentration $\left\langle\phi^{\prime \prime} \phi^{\prime \prime}\right\rangle^{1 / 2} / \Phi$. Two peaks of RMS pollutant concentration are observed in the first street canyon with pollutant source. The broad maximum ground-level $\left\langle\phi^{\prime \prime} \phi^{\prime \prime}\right\rangle^{1 / 2}$ is mainly due to the sharply elevated pollutant concentration right over the pollutant source. That it extends to the leeward side is a result of the primary clockwise recirculation in a street canyon in skimming flow. Another peak $\left\langle\phi^{\prime \prime} \phi^{\prime \prime}\right\rangle^{1 / 2}$ resides at the roof level. Because turbulence is the sole driving force 
for the pollutant mixing in isothermal conditions, the roof-level peak RMS pollutant concentration is attributed to the locally elevated concentration gradient. This roof-level maximum $\left\langle\phi^{\prime \prime} \phi^{\prime \prime}\right\rangle^{1 / 2}$ also signifies the importance of turbulence in the pollutant removal from a street canyon. It is noteworthy that the peak $\left\langle\phi^{\prime \prime} \phi^{\prime \prime}\right\rangle^{1 / 2}$ does not exactly coincide with the maximum wind shear on the leeward side but is shifted to the windward side, suggesting the importance of advection redistributing TKE from the leeward to the windward sides in a street canyon.

In the absence of pollutant source from the street canyon, the RMS pollutant concentration in the second street canyon is much smaller than that in the first. The broad peak of $\left\langle\phi^{\prime \prime} \phi^{\prime \prime}\right\rangle^{1 / 2}$ is on the windward side following the entrainment into the street canyon. The RMS pollutant concentration is unnoticeable in the rest of the street canyons, implying that the pollutant concentration is rather steady and uniform in the street canyons without any ground-level pollutant source.

\subsection{Pollutant Removal Mechanism}

A few studies have been performed to elucidate the pollutant removal mechanism from 2D street canyons. Lee and Park (1994) and Sini et al. (1996) used the exponential decay time constant and the integral dilution time scale to measure pollutant removal rate. Using wind tunnel measurements, the convective pollutant transfer velocity/coefficient have been proposed by Barlow and Belcher (2002) and Narita (2007) to compare the pollutant removal efficiency from street canyons of different aspect ratios. Likewise, Bentham and Britter (2003) and Bady et al. (2008) employed analytical solutions to derive pollutant exchange velocity, purging flow rate, 
visitation frequency (number of times of a pollutant particle enters the control volume and passes through it), and residence time. Using LES, Liu et al. (2005) modified the concept of air exchange rate (ACH) in building services engineering formulating the pollutant exchange rate $(\mathrm{PCH})$ to examine the pollutant removal from a $2 \mathrm{D}$ street canyon. The $\mathrm{PCH}$ of an idealized $2 \mathrm{D}$ street canyon flanked by buildings of equal height is defined as

$$
\mathrm{PCH}(t)=\int_{\Gamma}[\bar{w}(t) \bar{\phi}(t)]_{\text {roof }} \mathrm{d} \Gamma
$$

where the subscript roof signifies that the properties are normal to the roof of the street canyon $\Gamma$. In view of the direction of the vertical velocity $\bar{w}$, positive $\mathrm{PCH}$ represents pollutant removal while negative $\mathrm{PCH}$ pollutant entrainment. Decomposing PCH into the mean and turbulent components, and taking ensemble average yields

$$
\begin{aligned}
& \langle\mathrm{PCH}(t)\rangle=\langle\mathrm{PCH}\rangle \\
& \quad=\langle\overline{\mathrm{PCH}}\rangle+\left\langle\mathrm{PCH}^{\prime \prime}\right\rangle \\
& \quad=\int_{\Gamma}\left[\langle\bar{\phi}\rangle\langle\bar{w}\rangle+\left\langle\phi^{\prime \prime} w^{\prime \prime}\right\rangle\right]_{\text {roof }} \mathrm{d} \Gamma
\end{aligned}
$$

that measures the relative contributions from the mean $\langle\bar{\phi}\rangle\langle\bar{w}\rangle$ and turbulent $\left\langle\phi^{\prime \prime} w^{\prime \prime}\right\rangle$ pollutant fluxes to the total pollutant removal. Therefore, PCH has two parts, as defined in the integral Equation (13), one due to the mean values and the other the mean of the correlation between flows and pollutant concentration. In the current LES, $\langle\overline{\mathrm{PCH}}\rangle$ is negative (less than $10 \%$ of $\langle\mathrm{PCH}\rangle)$ in the first street canyon with pollutant source, signifying pollutant entrainment by mean flow. As such, the turbulent component $\left\langle\mathrm{PCH}^{\prime \prime}\right\rangle$ is responsible carrying pollutant away from the street canyon. 
Fig. 15 depicts the ensemble average mean pollutant flux $\langle\bar{\phi}\rangle\langle\bar{w}\rangle / \Phi / \mathrm{U}$ turbulent pollutant flux $\left\langle\phi^{\prime \prime} w^{\prime \prime}\right\rangle / \Phi / \mathrm{U}$ and total pollutant flux $\left(\langle\bar{\phi}\rangle\langle\bar{w}\rangle+\left\langle\phi^{\prime \prime} w^{\prime \prime}\right\rangle\right) / \Phi / \mathrm{U}$ along the roof level of the street canyons. Please note that only the first street canyon is installed with pollutant source. The ensemble average mean pollutant flux is decreased in the streamwise direction (Fig. 15a) that is attributed to the inhomogeneous ground-level pollutant source and the exponentially decaying pollutant concentration. The pollutant is removed $(\langle\bar{\phi}\rangle\langle\bar{w}\rangle / \Phi / \mathrm{U}$ $>0$ ) and is entrained $(\langle\bar{\phi}\rangle\langle\bar{w}\rangle / \Phi / \mathrm{U}<0)$ on the leeward and windward side, respectively, following the primary clockwise recirculation in the street canyons. As shown by the sharp roof-level $\langle\bar{\phi}\rangle\langle\bar{w}\rangle / \Phi / \mathrm{U}$, the pollutant is removed abruptly right at the roof-level windward edge because of the flow impingement. Fig. 15b shows that the turbulent pollutant flux largely accounts for the pollutant removal. Only a tiny negative $\left\langle\phi^{\prime \prime} w^{\prime \prime}\right\rangle / \Phi / \mathrm{U}$ is observed close to the roof-level leeward building edge, thus, its contribution to the overall pollutant entrainment is insignificant. Moreover, the turbulent pollutant flux is comparable to its mean counterpart only in the first street canyon with the pollutant source. In the rest of the street canyons, the turbulent pollutant flux is negligible, clarifying the different roles of mean and turbulent components in the total pollutant removal. We thus hypothesize that the pollutant removal mechanism in $2 \mathrm{D}$ street canyons is mainly governed by turbulent mixing, dilution, then advection out of the street canyon to the UBL to reduce the ground-level pollutant concentration.

Combining the mean and turbulent pollutant fluxes yields the total pollutant flux $\left(\langle\bar{\phi}\rangle\langle\bar{w}\rangle+\left\langle\phi^{\prime \prime} w^{\prime \prime}\right\rangle\right) / \Phi / \mathrm{U}$ (Fig. 15c). In the first street canyon, the net pollutant removal is positive that offsets the pollutant emission at the 
ground level. Moreover, $\langle\overline{\mathrm{PCH}}\rangle$ and $\left\langle\mathrm{PCH}^{\prime \prime}\right\rangle$ are comparable to each other. In the rest of the street canyons without pollutant source, $\left\langle\mathrm{PCH}^{\prime \prime}\right\rangle$ is smaller than $\langle\overline{\mathrm{PCH}}\rangle$ by an order of magnitude so the net $\langle\overline{\mathrm{PCH}}\rangle$ equals zero that carries pollutant into and out of the street canyons simultaneously.

\subsection{Coherent Structures}

Ensemble average quantities are used in the previous sections studying the turbulent transport in $2 \mathrm{D}$ street canyons. Additional perspective about the turbulent transport processes, especially the pollutant removal mechanism, could be accomplished by looking into the coherent structures of the instantaneous flow variables. These data are snapshots of the LES that are considered typical structures of flows and pollutant transport.

Fig. 16 compares the instantaneous vertical momentum flux $u^{\prime \prime} w^{\prime \prime}$ at different levels over and inside the street canyons. At $z=2 h$ in the UBL core, the flow is dominated by the coherent structures of negative vertical momentum flux, suggesting that most of the fast-moving (slow-moving) streamwise flowing air masses are downward (upward) moving (Fig. 16a). This negative correlation between the streamwise and vertical flows in turn signifies the majority momentum transport from the prevailing flow down to the lower UBL entraining into the street canyons. At a lower elevation $z=1.2 h$ close to the roof level (Fig. 16b), the vertical momentum flux is also mostly negative. Different from that in the UBL core, its structures are mildly elongated in the streamwise direction. Whereas, no alternative high- and low-speed elongated structures are clearly found yet. In the region very close to the roof level at $z$ $=1.05 \mathrm{~h}$ (Fig. 16c), the elongated flow structures no longer exist that are replaced by patches of negative vertical momentum flux over the street canyons. 
These downward moving coherent structures, which are partly attributed to the form drag of the buildings, transfer momentum into the street canyons through the shear layer at roof level. As shown in Fig. 16d, the negatively correlated roof-level streamwise and vertical velocities are consistent with the positive skewed streamwise velocity (Fig. 5) and the negative skewed vertical velocity (Fig. 7) along the roof level (Section 3.1.1). Momentum entrains down into the street canyon to drive the primary recirculation, the vertical momentum flux at the street-canyon mid level $(z=0.5 h)$ is therefore positive (Fig. 16e), suggesting the advection dominated momentum transport.

Fig. 17 illustrates the LES-calculated snapshots of streamwise slow-moving (Fig. 17a) and fast-moving (Fig. 17b) air masses. Similar to the flows in other studies available in literature, sparse air masses carrying negative momentum fluxes are found in the UBL demonstrating the downward momentum transfer from the prevailing flow. Slow-moving air masses, which are partly due to the drag of the buildings, are consistently observed at the roof level of the street canyons (Fig. 17a). These coherent structures are also dominated by the updrafts of positive fluctuating vertical velocity $w^{\prime \prime}$, that in turn suggests the characteristic vertical momentum transfer. These downward vertical momentum fluxes are also revealed in Fig. 16 and in wind tunnel experiments in the form of sweeps and ejections (Michioka et al., 2011a).

Fig. 18 switches the contours of vertical fluctuating velocity $w^{\prime \prime}$ to the fluctuating pollutant concentration $\phi^{\prime \prime}$ on the patches of air masses. Along the roof level, the fluctuating pollutant concentration is negative on those slow-moving air masses (Fig. 18a). Hence, polluted air masses slow down $\left(u^{\prime \prime}<0\right)$ and move upward $\left(w^{\prime \prime}>0\right)$ leading to the decreasing instantaneous 
pollutant concentration $\left(\phi^{\prime \prime}<0\right)$ over the street canyons. This momentum transfer, from the horizontal to the vertical, formulates the basic mechanism of pollutant removal from a street canyon in skimming flow. In the UBL aloft, fast-moving air masses lower down their pollutant concentration due to streamwise advection (Fig. 18b). It is noteworthy that the aforementioned upward-moving coherent structure was also revealed in the particle image velocimetry (PIV) experiments by Takimoto et al. (2011). They used the term flushing to represent this upward air movement across the entire street canyon. Recently, Michioka and Sato (2012), using different incoming turbulent flow structures, showed that the pollutant removal is attributed to the low-momentum fluid. The amount of pollutant removal is closely related to the size of the coherent structure.

As discussed mathematically in Section 3.3, the fluctuating vertical velocity $w^{\prime \prime}$ accounts for the pollutant removal from the street canyons to the UBL. Snapshots of downdrafts $\left(w^{\prime \prime}<0\right)$ and updrafts $\left(w^{\prime \prime}>0\right)$ are depicted in Figs. 19a and 19b, respectively. Large downdrafts with negative pollutant concentration fluctuation are identified at around $z=2 h$ (Fig. 19a), suggesting the downward fresh air entrainment for pollutant dilution. Updrafts are shown in Fig. 19b with positive fluctuating pollutant concentration. These uprising air masses carry pollutants from the street canyons to the roof level and finally to the UBL aloft governing the basic pollutant removal.

\section{Conclusions}

In view of the rapid urbanization and heavy vehicular pollutant emission, a numerical analysis using LES is carried out to advance our basic under- 
standing of pollutant removal from urban street canyons. Decomposing the roof-level vertical pollutant flux into its mean and turbulent components reveals that pollutant removal from a street canyon is dominated by turbulence. Turbulent mixing dilutes the ground-level pollutant which is then purged away by the prevailing flow. On the other hand, mean wind drives pollutant into and out of a street canyon simultaneously, ending up with insignificant net pollutant exchange. A detailed investigation of the statistic properties and coherent structures of the turbulence in the UBL unveils that the streamwise flows decelerate (accelerate) over the street canyons (buildings). The slow-moving flows are results of momentum entrainment into the street canyons driving the recirculating flows. Besides, the negative fluctuating streamwise velocity gives rise to the upward moving air masses carrying the pollutant out of a street canyon. These findings collectively formulate the basic turbulent pollutant removal mechanisms in urban street canyons in the skimming flow regimes. The results also shade some light on the functionality of turbulence over urban areas from the air quality perspective and arouse the benefit of promoting both mean winds and turbulence for pollutant removal from street level in dense compact cities.

\section{Acknowledgments}

This study was jointly supported by the Strategic Research Areas and Themes, Computational Sciences, and the University Research Committee Seed Funding Programme of Basic Research 200910159028, 201011159166, and 201111159166 of the University of Hong Kong. The computation is supported in part by a Hong Kong UGC Special Equipment Grant (SEG 
HKU09). The technical support from Lilian Y.L. Chan, Frankie F.T. Cheung, Tony W.K. Cheung, W.K. Kwan, and N.S. Mok with HKU ITS is appreciated. Last but not least, we deeply thank the anonymous reviewers for their constructive reviews and insightful comments.

\section{References}

Ahmad, K., Khare, M., Chaudhry, K. K., 2005. Wind tunnel simulation studies on dispersion at urban street canyons and intersections - a review. J. Wind Engg. \& Ind. Aerodyn. 93, 697-717.

Ashrafian, A., Andersson, H., Manhart, M., 2004. DNS of turbulent flow in rod-roughened channel. Int. J. Heat and Fluid Flow 25, 373-383.

Bady, M., Kato, S., Huang, H., 2008. Towards the application of indoor ventilation efficiency indices to evaluate the air quality of urban areas. Build. Environ. 43, 1991-2004.

Baklanov, A., 2009. Introduction to the problem and aims. In: Baklanov, A., Grimmond, S., Mahura, A., Athanassiadou, M. (Eds.), Meteorological and Air Quality Models for Urban Areas. Springer, Berlin Heidelberg.

Barlow, J. F., Belcher, S. E., 2002. A wind tunnel model for quantifying fluxes in the urban boundary layer. Boundary-Layer Meteorol. 104, 131-150.

Bentham, T., Britter, R. E., 2003. Spatially averaged flow within obstacle arrays. Atmos. Environ. 37, 2037-2043.

Britter, R. E., Di Sabatino, S., Caton, F., Cooke, K. M., Simmonds, P. G., Nickless, G., 2002. Results from three field tracer experiments on the neigh- 
bourhood scale in the city of Birmingham UK. Water, Air, and Soil Pollution: Focus 2, 79-90.

Brown, M. J., Lawson, R. E., Decroix, D. S., Lee, R. L., 2000. Mean flow and turbulence measurements around a 2-D array of buildings in a wind tunnel. In: Proceedings of the 11th joint AMS/AWMA Conference in Applied Air Pollution Meteorology, January 2005. Long Beach, CA, USA.

Cai, X. M., Barlow, J. F., Belcher, S. E., 2008. Dispersion and transfer of passive scalars in and above street canyons - large-eddy simulations. Atmos. Environ. 42, 5885-5895.

Chang, C.-H., Meroney, R. N., 2001. Numerical and physical modeling of bluff body flow and dispersion in urban street canyons. J. Wind Engg. \& Ind. Aerodyn. 89, 1325-1334.

Chang, C.-H., Meroney, R. N., 2003. Concentration and flow distributions in urban street canyons: wind tunnel and computational data. J. Wind Engg. \& Ind. Aerodyn. 91, 1141-1154.

Chang, D., Song, Y., Liu, B., 2009. Visibility trends in six megacities in china 1973-2007. Atmospheric Research 94, 161-167.

Chen, J., Wang, W., Zhang, J., Liu, H., Ren, L., Liu, X., Zhang, W., Wang, X., 2009. Characteristics of gaseous pollutants near a main traffic line in beijing and its influencing factors. Atmospheric Research 94, 470-480.

Cheng, W. C., Liu, C.-H., 2011. Large-eddy simulation of flow and pollutant transport in and above two-dimensional idealized street canyons. Boundary-Layer Meteorol. 139, 411-437. 
Coceal, O., Thomas, T. G., Castro, I. P., Belcher, S. E., 2006. Mean flow and turbulence statistics over groups of urban-like cubical obstacles. BoundaryLayer Meteorol. 121, 491-519.

Cui, Z. Q., Cai, X. M., Baker, C. J., 2004. Large-eddy simulation of turbulent flow in a street canyon. Q. J. R. Meteorol. Soc. 130, 1373-1394.

Davidson, M. J., Mylne, K. R., Jones, C. D., Philips, J. C., Perkins, R. J., Fung, J. C. H., Hunt, J. C. R., 1995. Plume dispersion through large groups of obstacles - a field investigation. Atmos. Environ. 29, 3245-3256.

Douglas, J., Gasiorek, J., Swaffield, J., 1995. Fluid Mechanics, 3rd Edition. Longman Scientific \& Technical, Essex, UK.

Hanna, S. R., Brown, M. J., Camelli, F. E., Chan, S. T., Coirier, W. J., Hansen, O. R., Huber, A. H., Kim, S., Reynolds, R. M., 2006. Detailed simulations of atmospheric flow and dispersion in downtown Manhattan - an application of five computational fluid dynamics models. BAMS 87, $1713-1726$.

Jiang, Y., Liu, H., Sang, J., Zhang, B., 2007. Numerical and experimental studies on flow and pollutant dispersion in urban street canyons. Adv. Atmos. Sci. 24, 111-125.

Kanda, M., 2006. Large-eddy simulations on the effects of surface geometry of building arrays on turbulent organized structures. Boundary-Layer Meteorol. 118, 151-168.

Kastner-Klein, P., Plate, E. J., 1999. Wind-tunnel study of concentration fields in street canyons. Atmos. Environ. 33, 3973-3979. 
Kim, J., Moin, P., Moser, R., 1987. Turbulence statistics in fully developed channel flow at low Reynolds number. J. Fluid Mech. 177, 133-166.

Kim Oanh, N. T., Martel, M., Pongkiatkul, P., Berkowicz, R., 2008. Determination of fleet hourly emission and on-road vehicle emission factor using integrated monitoring and modeling approach. Atmospheric Research 89, $223-232$.

Landsberg, H. E., 1970. Man-made climatic changes. Energy 170, 1265-1274.

Lee, I. Y., Park, H. M., 1994. Parameterization of the pollutant transport and dispersion in urban street canyons. Atmos. Environ. 28, 2343-2349.

Letzel, M. O., Krane, M., Raasch, S., 2008. High resolution urban large-eddy simulation studies from street canyon to neighbourhood scale. Atmos. Environ. 42, 8770-8784.

Li, X.-X., Liu, C.-H., Leung, D. Y. C., Lam, K. M., 2006. Recent progress in CFD modeling of wind field and pollutant transport in street canyons. Atmos. Environ. 40, 5640-5658.

Liu, C.-H., Barth, M. C., 2002. Large-eddy simulation of flow and scalar transport in a modeled street canyon. J. Applied Meteoro. 41, 660-673.

Liu, C.-H., Leung, D. Y. C., Barth, M. C., 2005. On the prediction of air and pollutant exchange rates in street canyons of different aspect ratio using large-eddy simulation. Atmos. Environ. 39, 1567-1574.

Louka, P., Belcher, S. E., Harrison, R. G., 2000. Coupling between air flow in 
streets and the well-developed boundary layer aloft. Atmos. Environ. 34, $2613-2621$.

Macdonald, R. W., Griffiths, R. F., Hall, D. J., 1998. A comparison of results from scaled field and wind tunnel modelling of dispersion in arrays of obstacles. Atmos. Environ. 32, 3845-3862.

Mazzeo, N. A., Venegas, L. E., 1991. Air pollution model for an urban area. Atmospheric Research 26, 165-179.

Meroney, R. A., Pavageau, M., Rafailidis, S., Schatzmann, M., 1996. Study of line source characteristics for 2-D physical modelling of pollutant dispersion in street canyons. J. Wind Engg. \& Ind. Aerodyn. 90, 321-339.

Michioka, T., Sato, A., 2012. Effect of incoming turbulent structure on pollutant removal from two-dimensional street canyon. Boundary Layer Meteorol. 145, 469-484.

Michioka, T., Sato, A., Sada, K., 2011a. Wind-tunnel experiments for gas dispersion in an atmospheric boundary layer with large-scale turbulent motion. Boundary Layer Meteorol. 141, 35-51.

Michioka, T., Sato, A., Takimoto, H., Kanda, M., 2011b. Large-eddy simulation for the mechanism of pollutant removal from a two-dimensional street canyon. Boundary Layer Meteorol. 138, 195-213.

Minoura, H., 1999. Some characteristics of surface ozone concentration observed in an urban atmosphere. Atmospheric Research 51, 153-169. 
Nagaosa, R., 1999. Direct numerical simulation of vortex structures and turbulent shear transfer across a free surface in a fully devloped turbulence. Phys. Fluids 11, 1581-1595.

Narita, K., 2007. Experimental study of the transfer velocity for urban surfaces with a water evaporation method. Boundary-Layer Meteorol. 122, 293-320.

Notario, A., Bravo, I., Adame, J. A., Díaz-de Mera, Y., Aranda, A., Rodríguez, A., Rodríguez, D., 2012. Analysis of $\mathrm{NO}, \mathrm{NO}_{2}, \mathrm{NO}_{\mathrm{x}}, \mathrm{O}_{3}$ and oxidant $\left(\mathrm{OX}=\mathrm{O}_{3}+\mathrm{NO}_{2}\right)$ levels measured in a metropolitan area in the southwest of iberian Peninsula. Atmospheric Research 104-105, 217-226.

Oke, T. R., 1988. Street design and urban canopy layer climate. Energy Bldg. $11,103-113$.

OpenFOAM, 2013. OpenFOAM: The open source CFD toolbox. Http://www.openfoam.com/.

Parrish, D. D., Zhu, T., 2009. Clean air for megacities. Science 326, 674-675.

Pasquill, F., 1983. Atmospheric Diffusion. John Wiley \& Sons, New York, USA.

Pavageau, M., Schatzmann, M., 1999. Wind tunnel measurements of concentration fluctuations in an urban street canyon. Atmos. Environ. 33, 3961-3971.

Piringer, M., Joffre, S., Baklanov, A., Christen, A., Deserti, M., De Ridder, K., Emeis, S., Mestayer, P. amd Tombrou, M., Middleton, D., Baumann- 
Stanzer, K., Dandou, A., Karppinen, A., Burzynski, J., 2007. The surface energy balance and the mixing height in urban areas - activities and recommendations of COST-Action 715. Boundary-Layer Meteorol. 124, 2-24.

Pope, S. B., 2009. Turbulent flow, sixth Edition. Cambridge University Press, Cambridge, UK.

Rotach, M. W., Vogt, R., Bernhofer, C., Batchvarova, E., Christen, A., Clappier, A., Feddersen, B., Gryning, S.-E., Martucci, G., Mayer, H., Mitev, V., Oke, T. R., Parlow, E., Richner, H., Roth, M., Roulet, Y.-A., D., R., Salmond, J. A., Schatzmann, M., Voogt, J. A., 2005. BUBBLE - an urban boundary layer meteorology project. Theor. Appl. Climatol. 81, 231-261.

Roth, M., 2000. Review of atmospheric turbulence over cities. Q. J. R. Meteorol. Soc. 126, 941-990.

Schumann, U., 1975. Subgrid scale model for finite difference simulations of turbulent flows in plane channels and annuli. J. Comp. Phys. 18, 376-404.

Sini, J. F., Anquetin, S., Mestayer, P. G., 1996. Pollutant dispersion and thermal effects in urban street canyons. Atmos. Environ. 30, 2659-2677.

Smagorinsky, J., 1963. General circulation experiments with the primative equations I: The basic experiment. Month. Weath. Rev. 91, 99-165.

Spalding, D. B., 1962. A new analytical expression for the drag of a flat plate valid for both the turbulent and laminar regimes. J. Heat and Mass Transfer 5, 1133-1138. 
Takimoto, H., Sato, A., Barlow, J. F., Moriwaki, R., Inagaki, A., Onomura, S., Kanda, M., 2011. Particle image velocimetry measurements of turbulent flow within outdoor and indoor urban scale models and flushing motions in urban canopy layers. Boundary-Layer Meteorol. 140, 295-314.

Tu, J., Xia, Z.-G., Wang, H., Li, W., 2007. Temporal variations in surface ozone and its precursors and meteorological effects at an urban site in china. Atmospheric Research 85, 310-337.

United Nation, 2008. World Urbanization Prospects: The 2007 Revision Highlight. United Nation, New York.

Vardoulakis, S., Fisher, B.-E., Pericleous, K., Gonzalez-Flesca, N., 2003. Modelling air quality in street canyons: A review. Atmos. Environ. 37, $155-182$

Wong, C. C. C., Liu, C.-H., 2010a. On the pollutant plume dispersion in the urban canopy layer over 2D idealized street canyons: a large-eddy simulation approach. In: European Geosciences Union General Assembly 2010, May 2 to 7, 2010. Vienna, Austria.

Wong, C. C. C., Liu, C.-H., 2010b. Pollutant removal, dispersion and entrainment over two-dimensional idealized street canyons: an LES approach. In: American Geophysical Union Fall Meeting 2010, December 13 to 17, 2010. San Francisco, California, USA.

Wood, R. C., Arnold, S. J., Balogun, A. A., Barlow, J. F., Belcher, S. E., Britter, R. E., Cheng, H., Dobre, A., Lingard, J. J. N., Martin, D., Neophytou, M. K., Petersson, F. K., Robins, A. G., Smallcross, D. E., Smalley, 
R. J., Tate, J. E., Tomlin, A. S., White, I. R., 2009. Dispersion experiments in central London. Q. J. R. Meteorol. Soc. 90, 955-969.

Yee, E., Gailis, R. M., Hill, A., Hilderman, T., Kiel, D., 2006. Comparison of wind-tunnel and water-channel simulations of plume dispersion through a large array of obstacles with a scaled field experiment. Boundary-Layer Meteorol. 121, 389-432. 


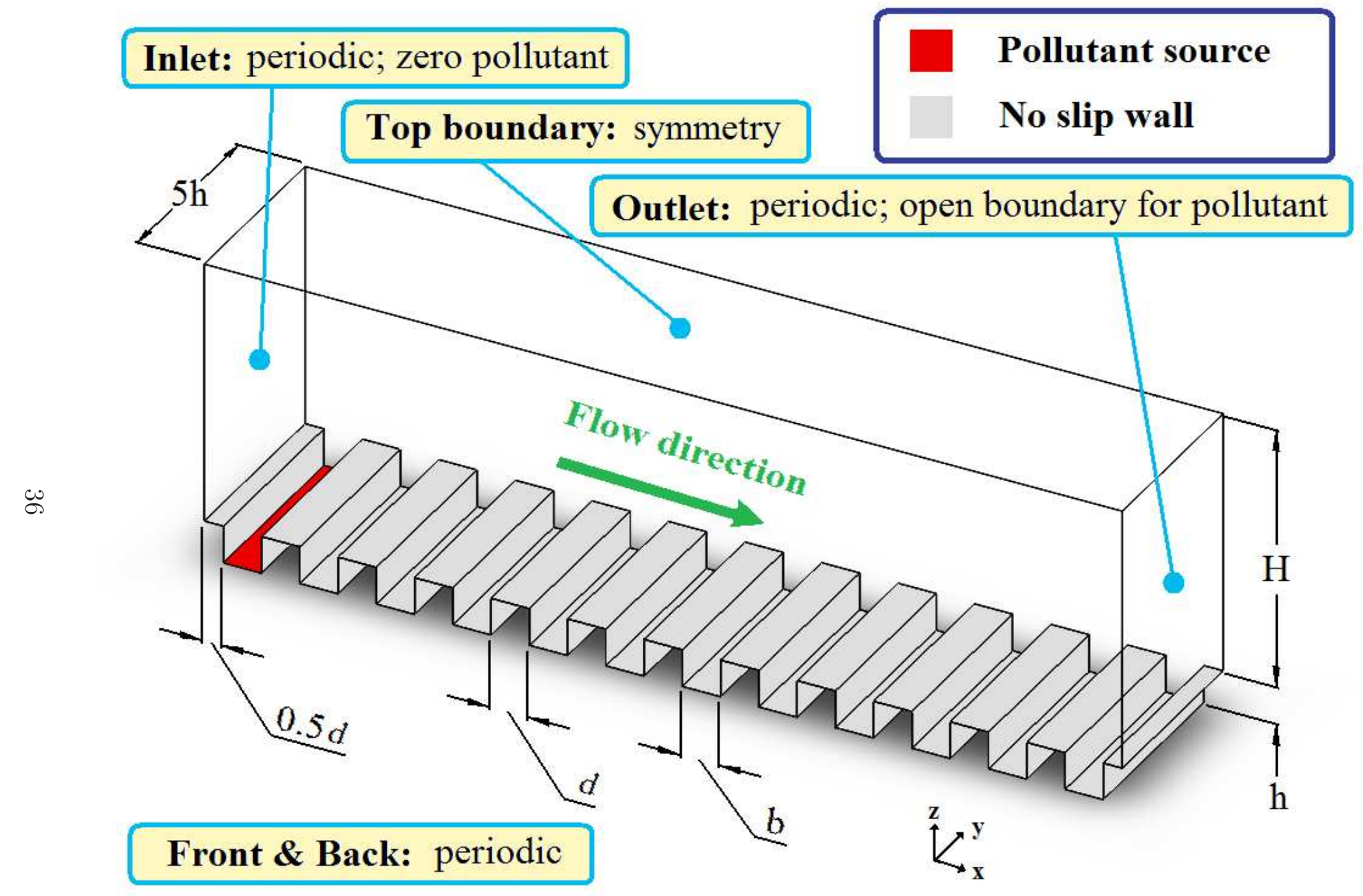

Figure 1: Computational domain of the LES. Note that $d=b=h$ in the current study. 


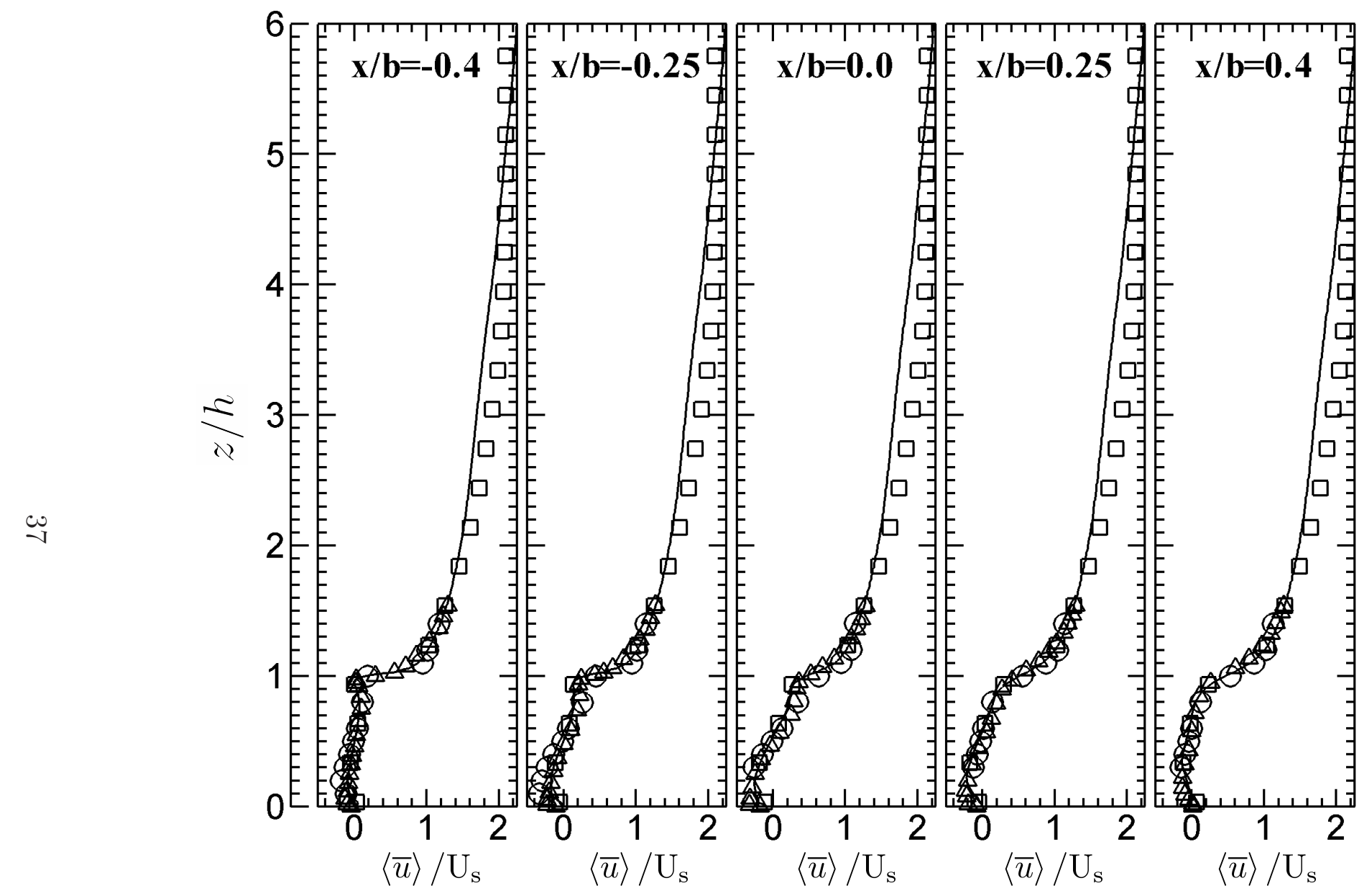

Figure 2: Vertical profiles of the ensemble average streamwise velocity $\langle\bar{u}\rangle / \mathrm{U}_{\mathrm{s}}$. ०: Brown et al. $(2000) ; \Delta$ : Cui et al. (2004); $\square$ : LES of Cheng and Liu (2011); and - : current LES; 


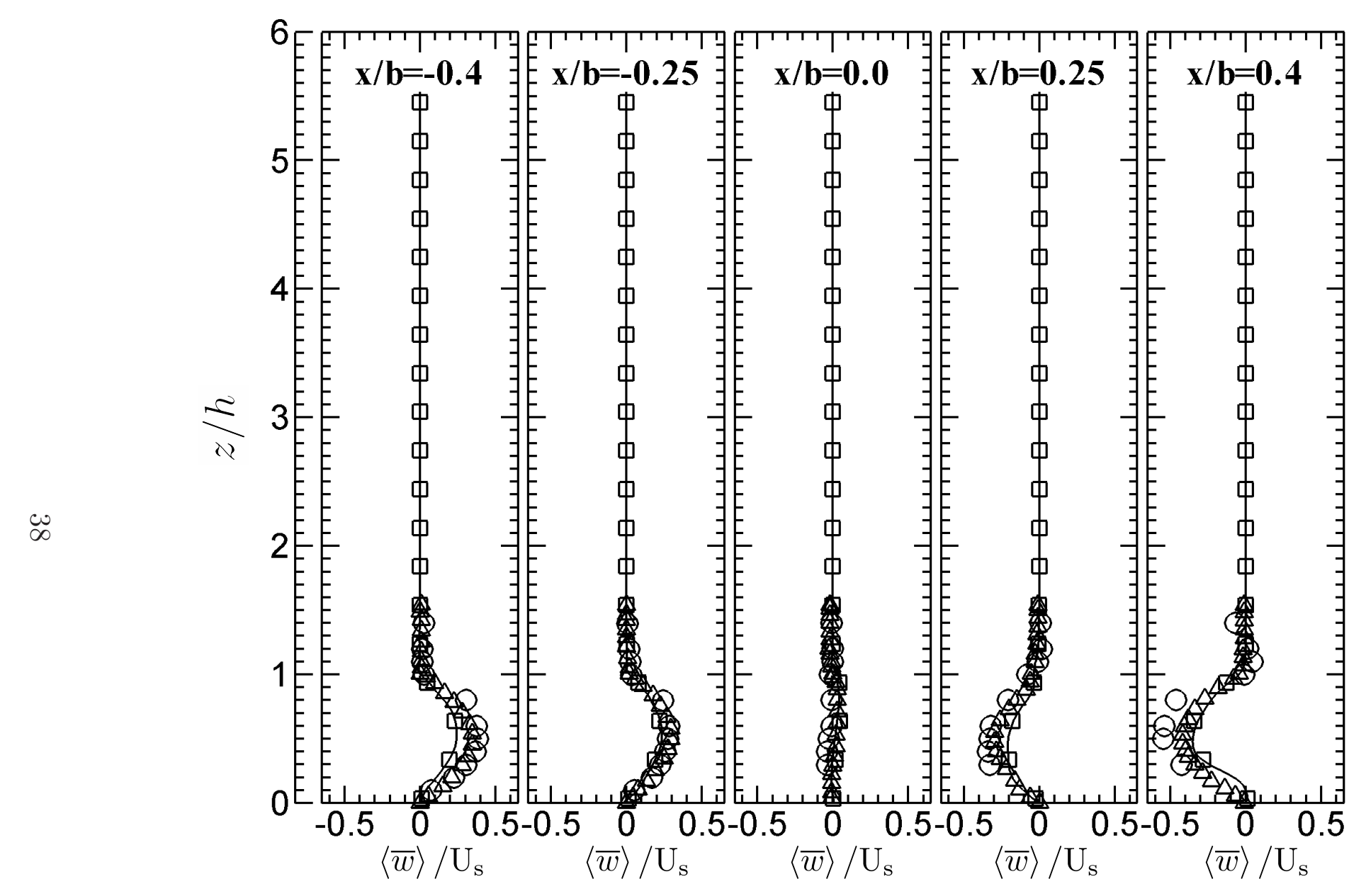

Figure 3: Vertical profiles of the ensemble average vertical velocity $\langle\bar{w}\rangle / \mathrm{U}_{\mathrm{s}}$. ०: Brown et al. (2000); $\Delta$ : Cui et al. (2004); $\square$ : LES of Cheng and Liu (2011); and - : current LES; 


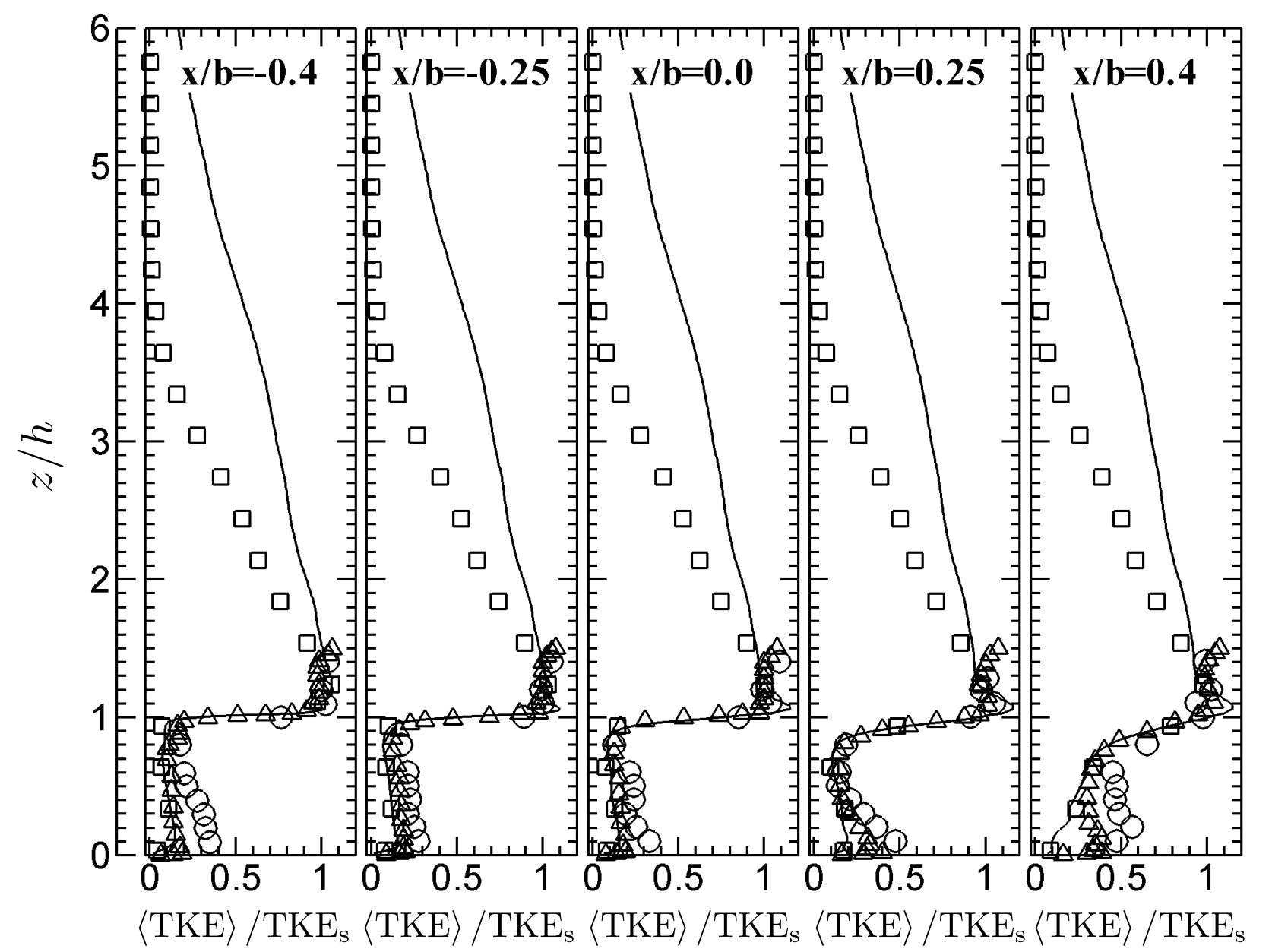

Figure 4: Vertical profiles of the ensemble average turbulent kinetic energy $\langle\mathrm{TKE}\rangle / \mathrm{TKE}_{\mathrm{s}}$. ०: Brown et al.

(2000); $\Delta$ : Cui et al. (2004); $\square$ : LES of Cheng and Liu (2011); and - : current LES; 


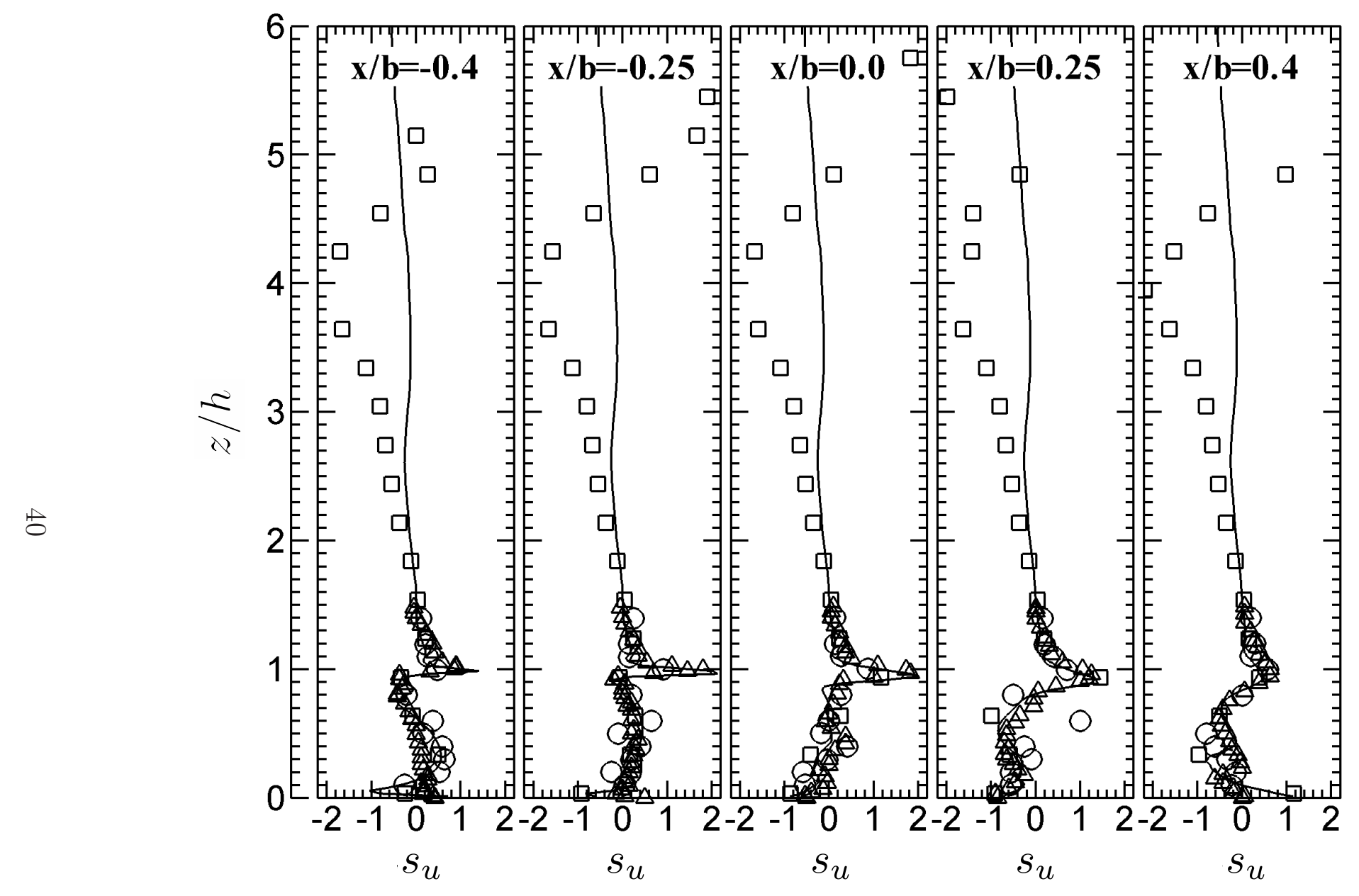

Figure 5: Vertical profiles of the skewness of the streamwise velocity $s_{u}$. ०: Brown et al. (2000); $\Delta$ : Cui et al. (2004); $\square$ : LES of Cheng and Liu (2011); and - : current LES; 


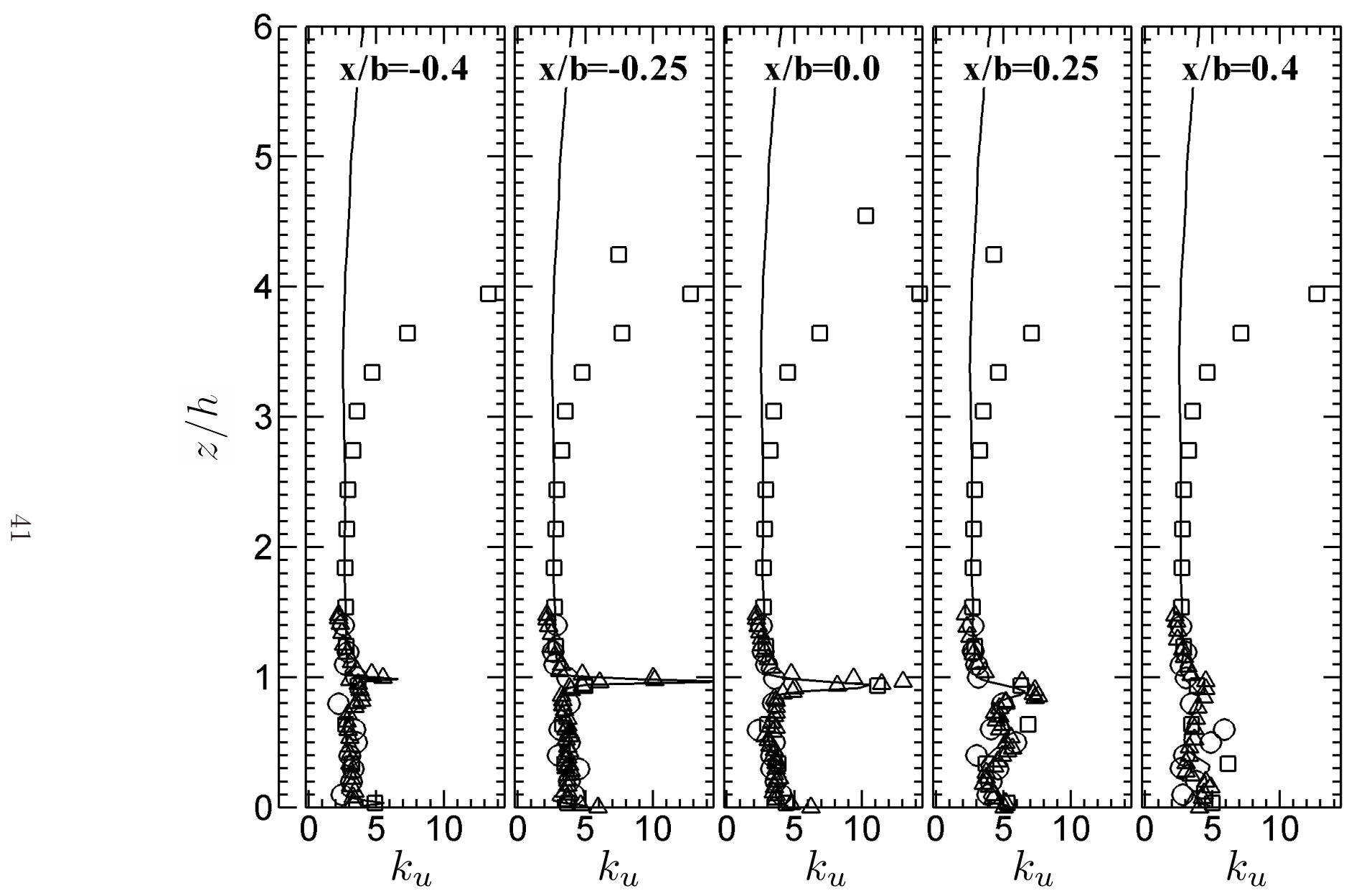

Figure 6: Vertical profiles of the kurtosis of the streamwise velocity $k_{u}$. ०: Brown et al. (2000); $\Delta$ : Cui et al. (2004); $\square$ : LES of Cheng and Liu (2011); and - : current LES; 


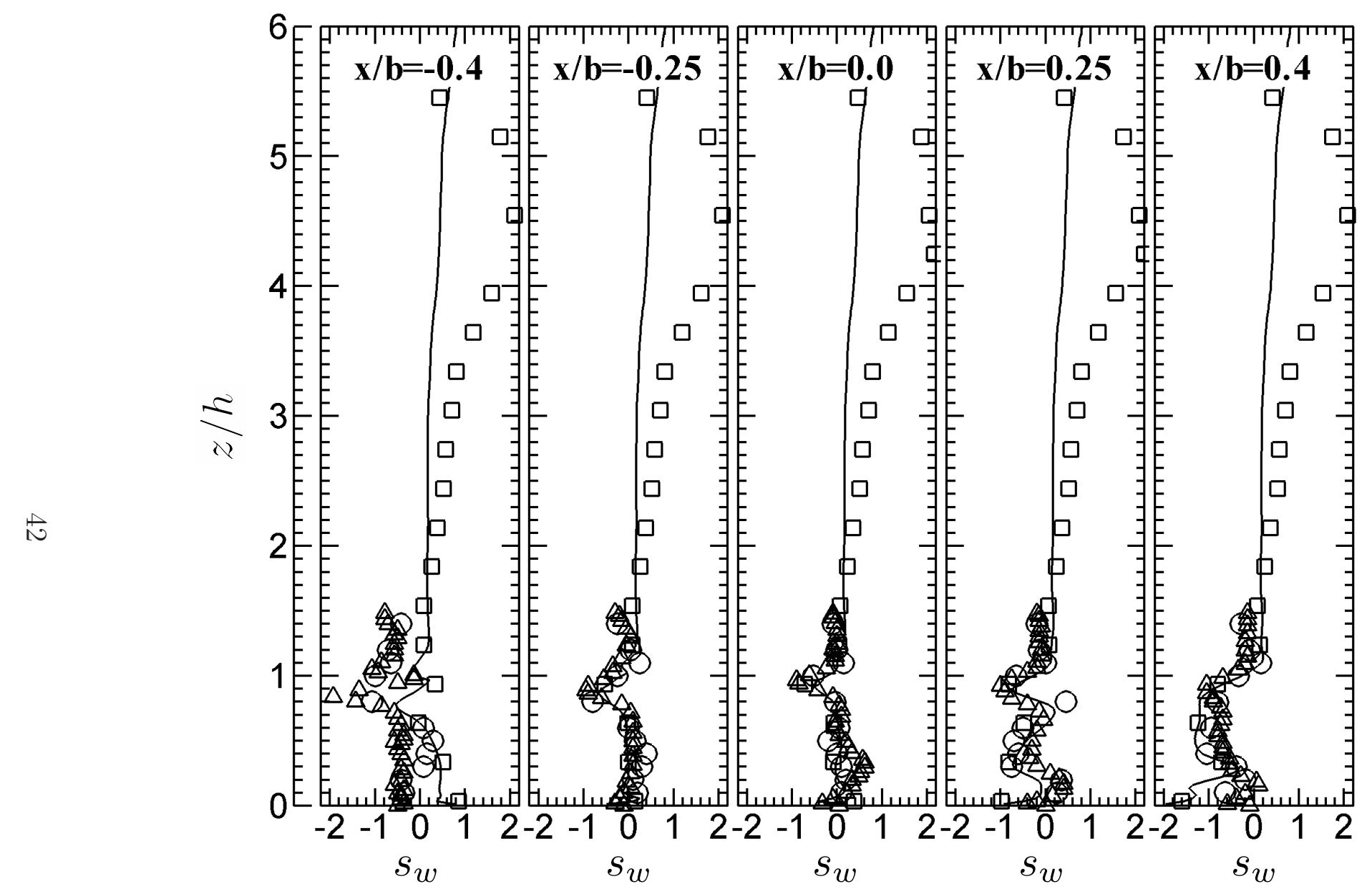

Figure 7: Vertical profiles of the skewness of the vertical velocity $s_{w}$. o: Brown et al. (2000); $\Delta$ : Cui et al. (2004); $\square$ : LES of Cheng and Liu (2011); and - : current LES; 


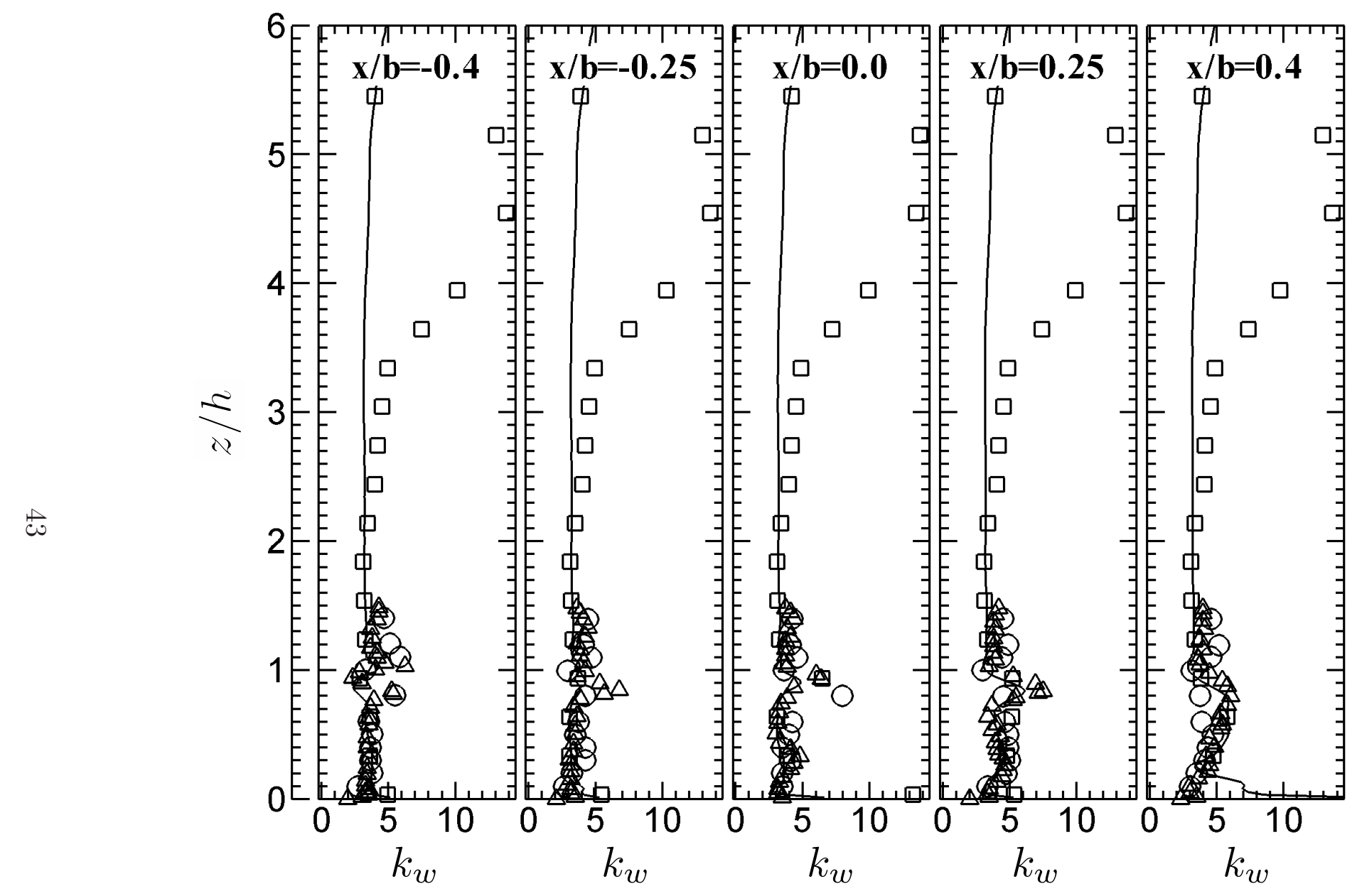

Figure 8: Vertical profiles of the kurtosis of the vertical velocity $k_{w}$. ०: Brown et al. (2000); $\Delta$ : Cui et al. (2004); $\square$ : LES of Cheng and Liu (2011); and -: current LES; 


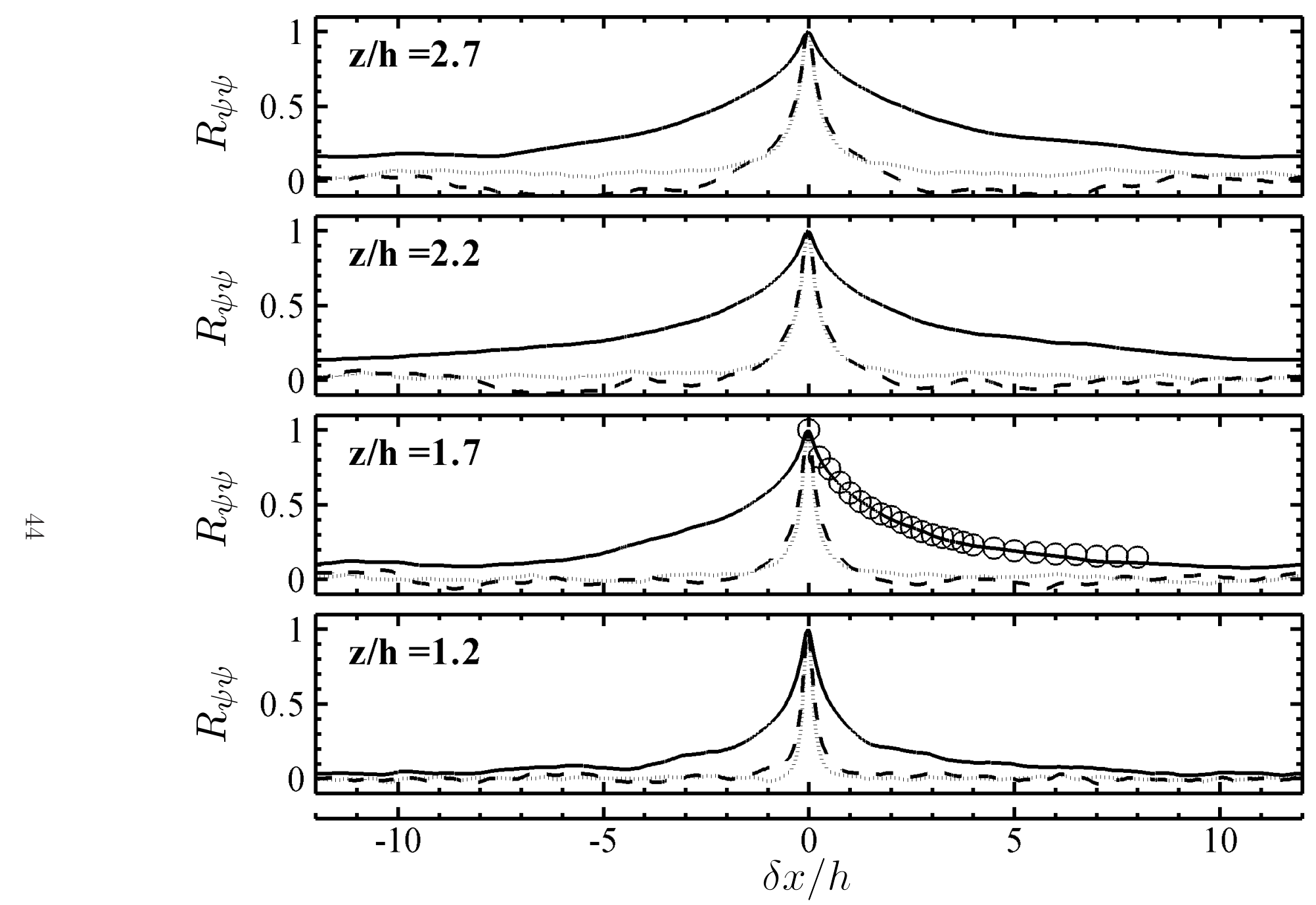

Figure 9: Autocorrelation $R_{\psi \psi}\left(x_{0}=0, \delta x\right)$ in the streamwise direction $x .-: R_{u u} ;------: R_{v v}$; and $\cdots \cdots: R_{w w}$ of current LES. Also shown is $R_{u u}$ over an array of cubes. o: Coceal et al. (2006). 


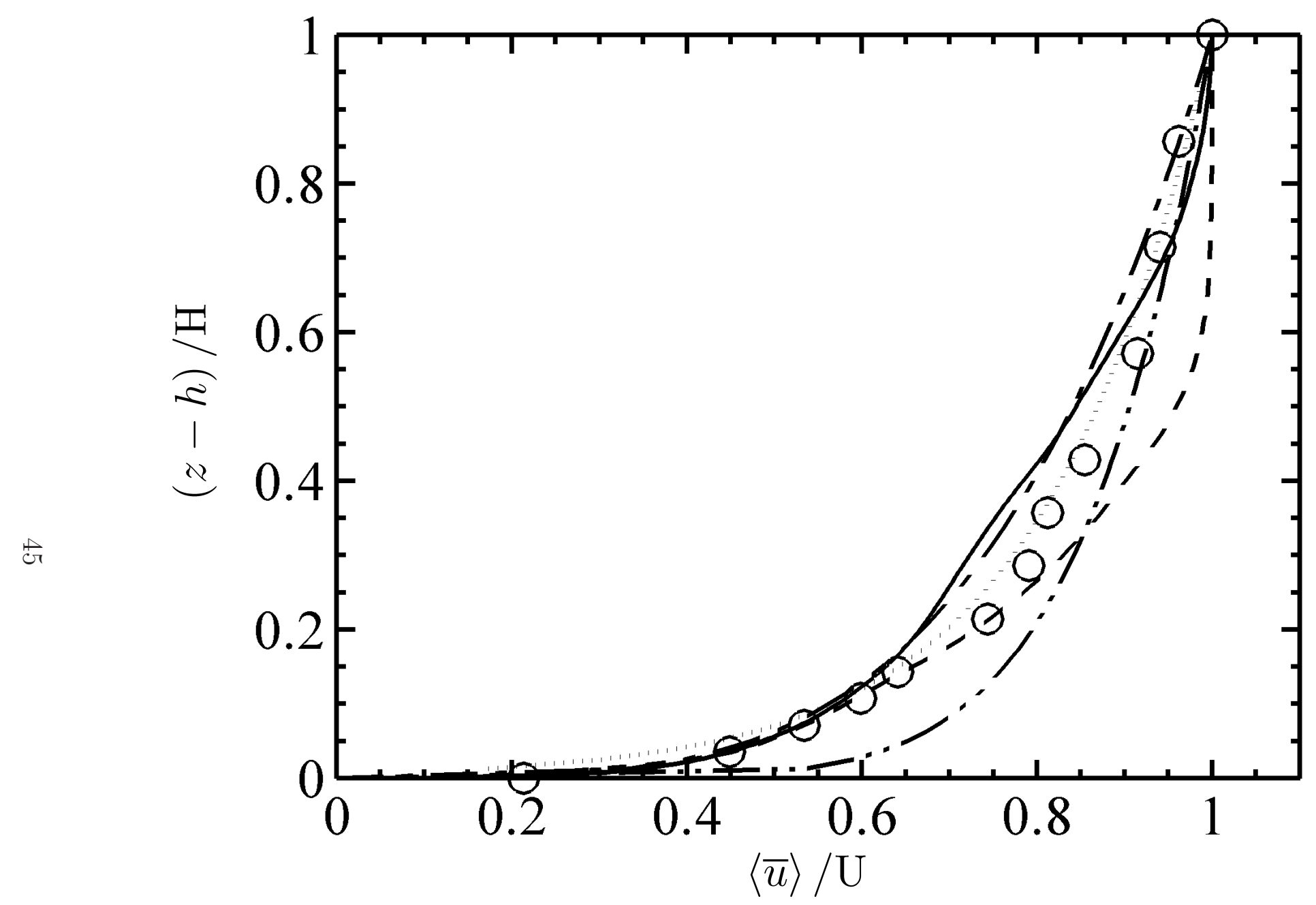

Figure 10: Vertical profiles of dimensionless streamwise velocity $\langle\bar{u}\rangle / \mathrm{U}$. — $~$ : current LES; - - - - --: Cheng and Liu (2011); o: Coceal et al. (2006); - - - - -: 1/4 power law; $-\cdots-\cdots-$ : 1/7 power law; and $\cdots \cdot \cdot$ : log law. 


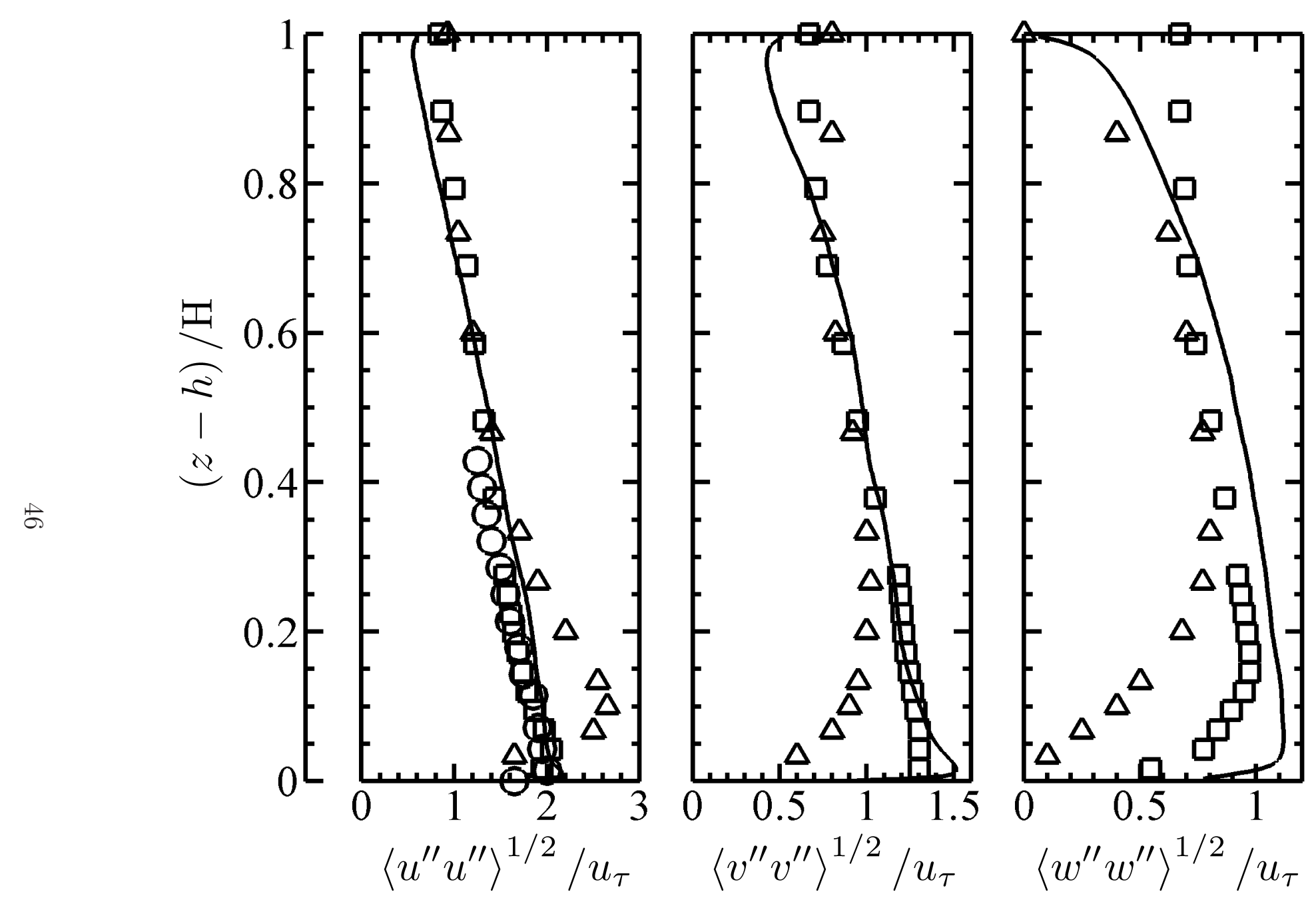

Figure 11: Vertical profiles of dimensionless root-mean-square velocity fluctuation $\left\langle u^{\prime \prime} u^{\prime \prime}\right\rangle^{1 / 2} / u_{\tau}$. — : current LES; $\Delta$ : Nagaosa (1999); $\square$ : Ashrafian et al. (2004); and o: Coceal et al. (2006). 


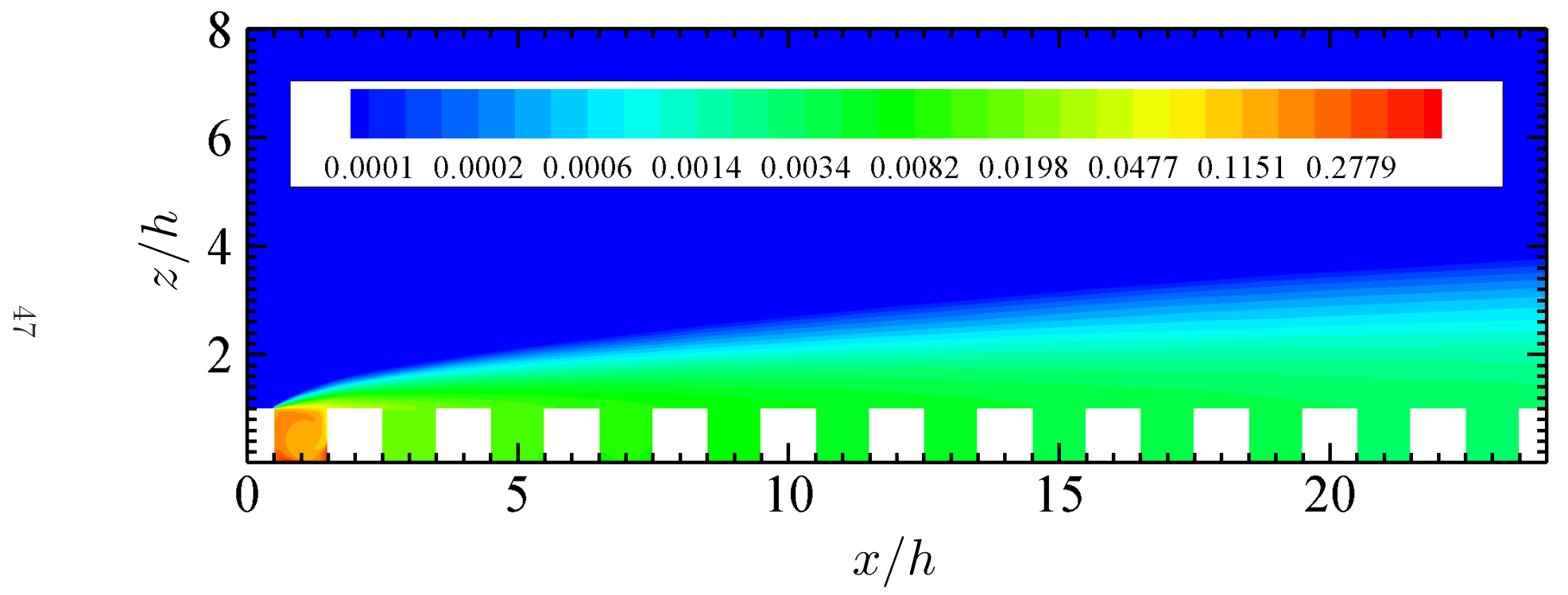

Figure 12: Contours of ensemble average pollutant concentration $\langle\bar{\phi}\rangle / \Phi$ on the vertical $x-z$ plane. 


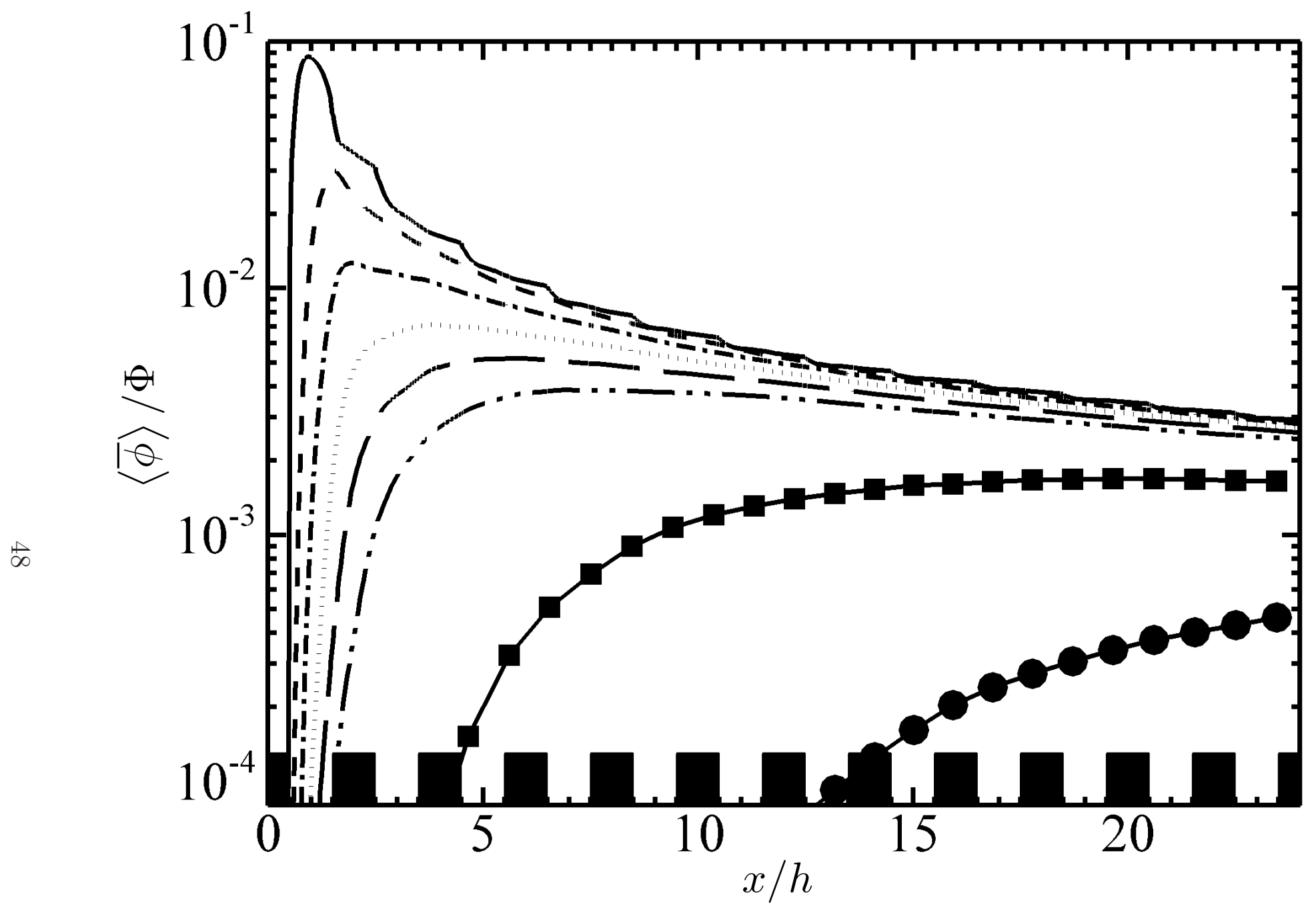

Figure 13: Ensemble average pollutant concentration $\langle\bar{\phi}\rangle / \Phi$ plotted as a function of streamwise distance $x / h$ at different elevations $z=:-\frac{\square}{\square} ;------: 1.1 h ;-\cdot-\cdot-: 1.2 h ; \cdots \cdots: 1.3 h$;

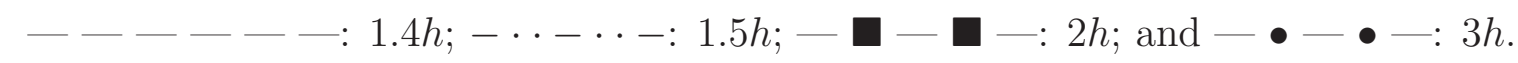




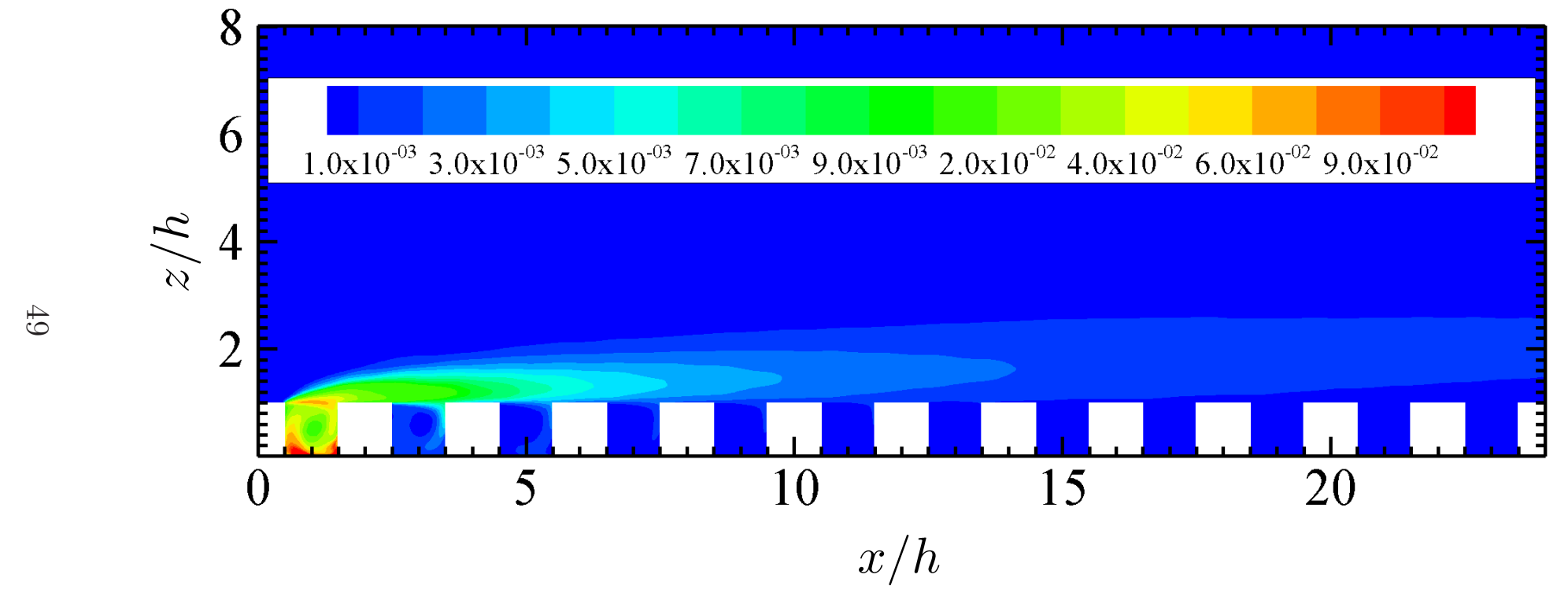

Figure 14: Contours of root-mean-square pollutant concentration $\left\langle\phi^{\prime \prime} \phi^{\prime \prime}\right\rangle^{1 / 2} / \Phi$ on the vertical $x$ - $z$ plane. 

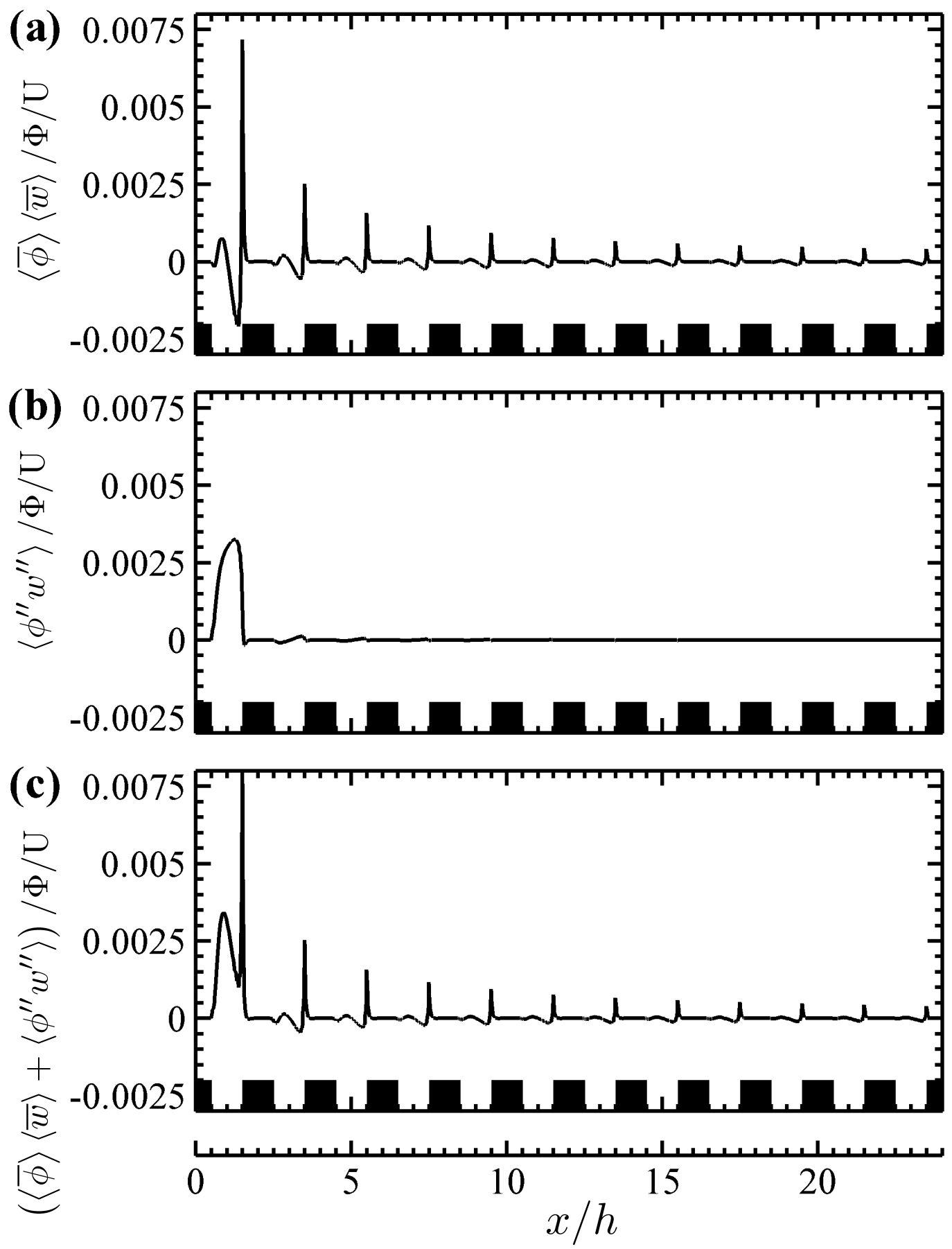

Figure 15: Ensemble average vertical pollutant flux along the roof level.

(a). Mean component $\langle\bar{\phi}\rangle\langle\bar{w}\rangle / \Phi / \mathrm{U} ; \quad$ (b). turbulent component $\left\langle\phi^{\prime \prime} w^{\prime \prime}\right\rangle / \Phi / \mathrm{U} ;$ and (c). total vertical pollutant flux $\left(\langle\bar{\phi}\rangle\langle\bar{w}\rangle+\left\langle\phi^{\prime \prime} w^{\prime \prime}\right\rangle\right) / \Phi / \mathrm{U}$. 


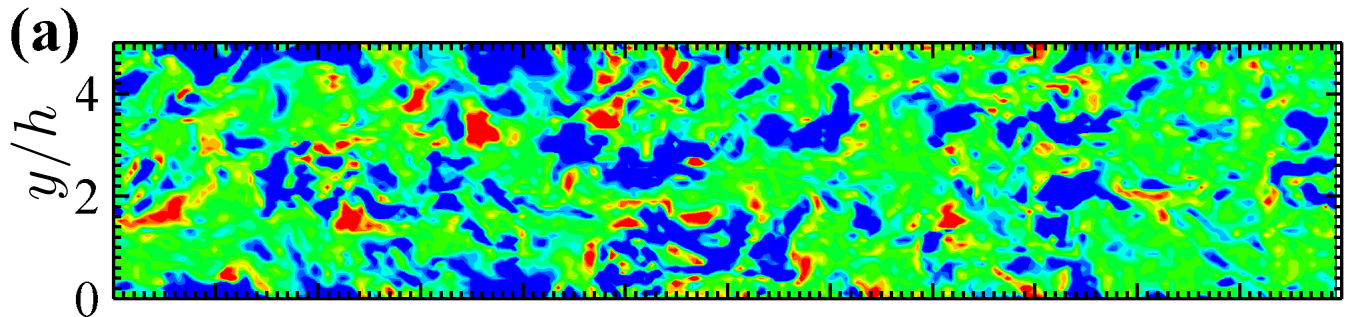

(b)

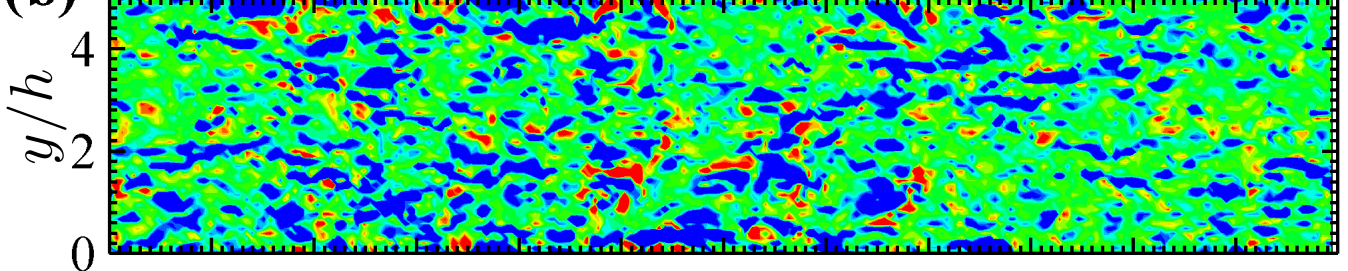

(c)

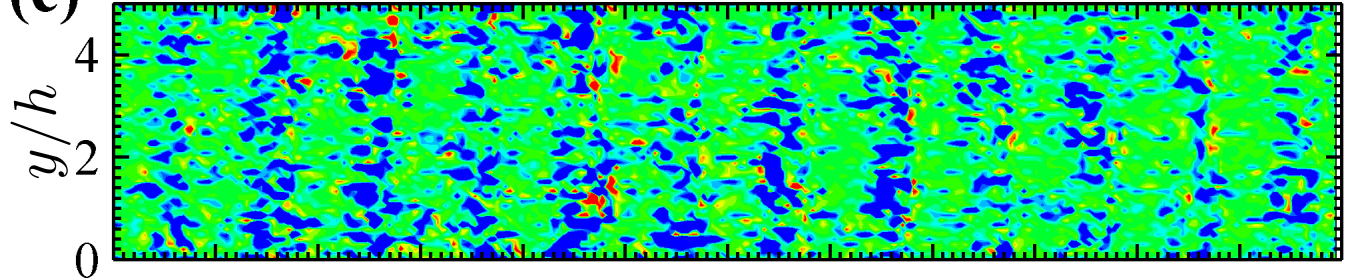

(d)

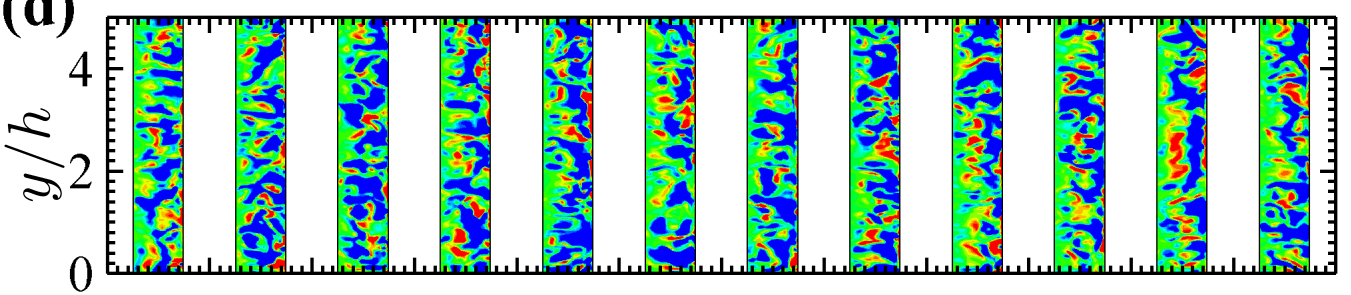

(e)

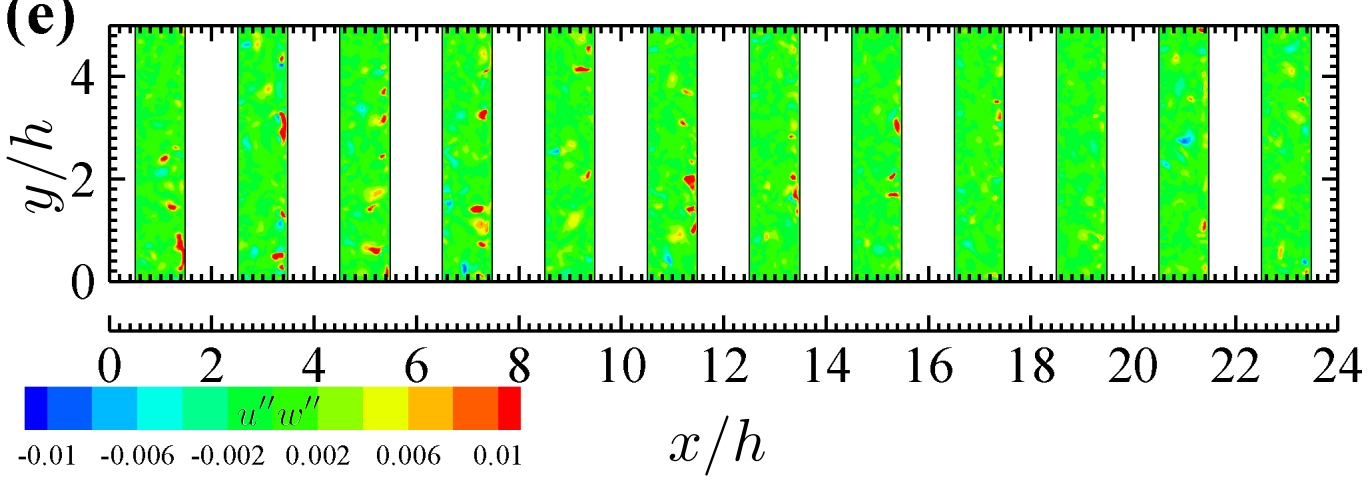

Figure 16: Contours of vertical momentum flux $u^{\prime \prime} w^{\prime \prime} / \mathrm{U}^{2}$ on the horizontal planes at $z=(\mathrm{a}) .2 h ;(\mathrm{b}) .1 .2 h ;(\mathrm{c}) .1 .05 h ;(\mathrm{d}) . h$; and (e). $0.5 h$. 


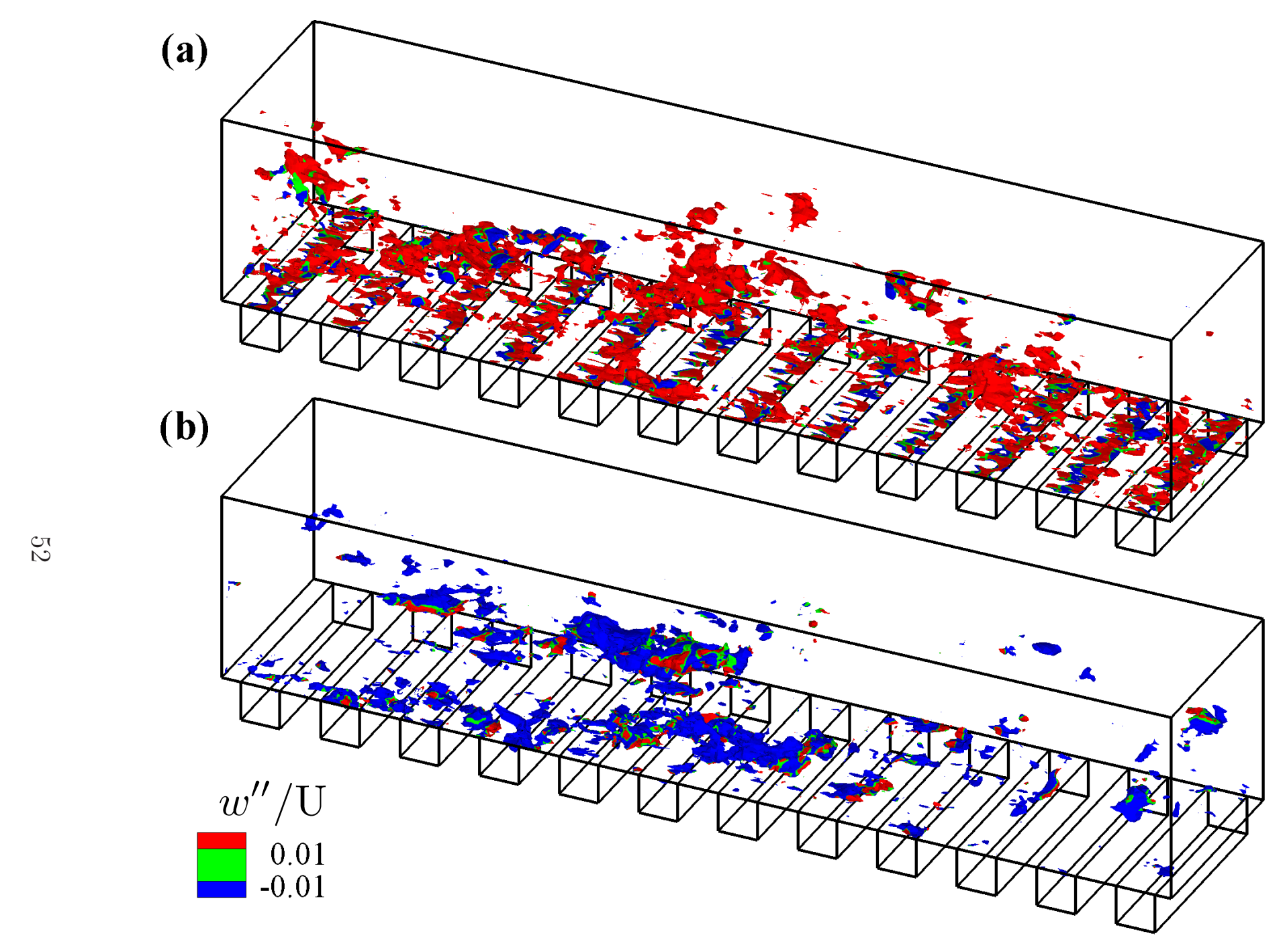

Figure 17: Isosurface of streamwise fluctuating velocity $u^{\prime \prime}=:$ (a). $-0.25 \mathrm{U}$ and (b). $0.25 \mathrm{U}$. Also shown are the contours of vertical fluctuating velocity $w^{\prime \prime} / \mathrm{U}$. 


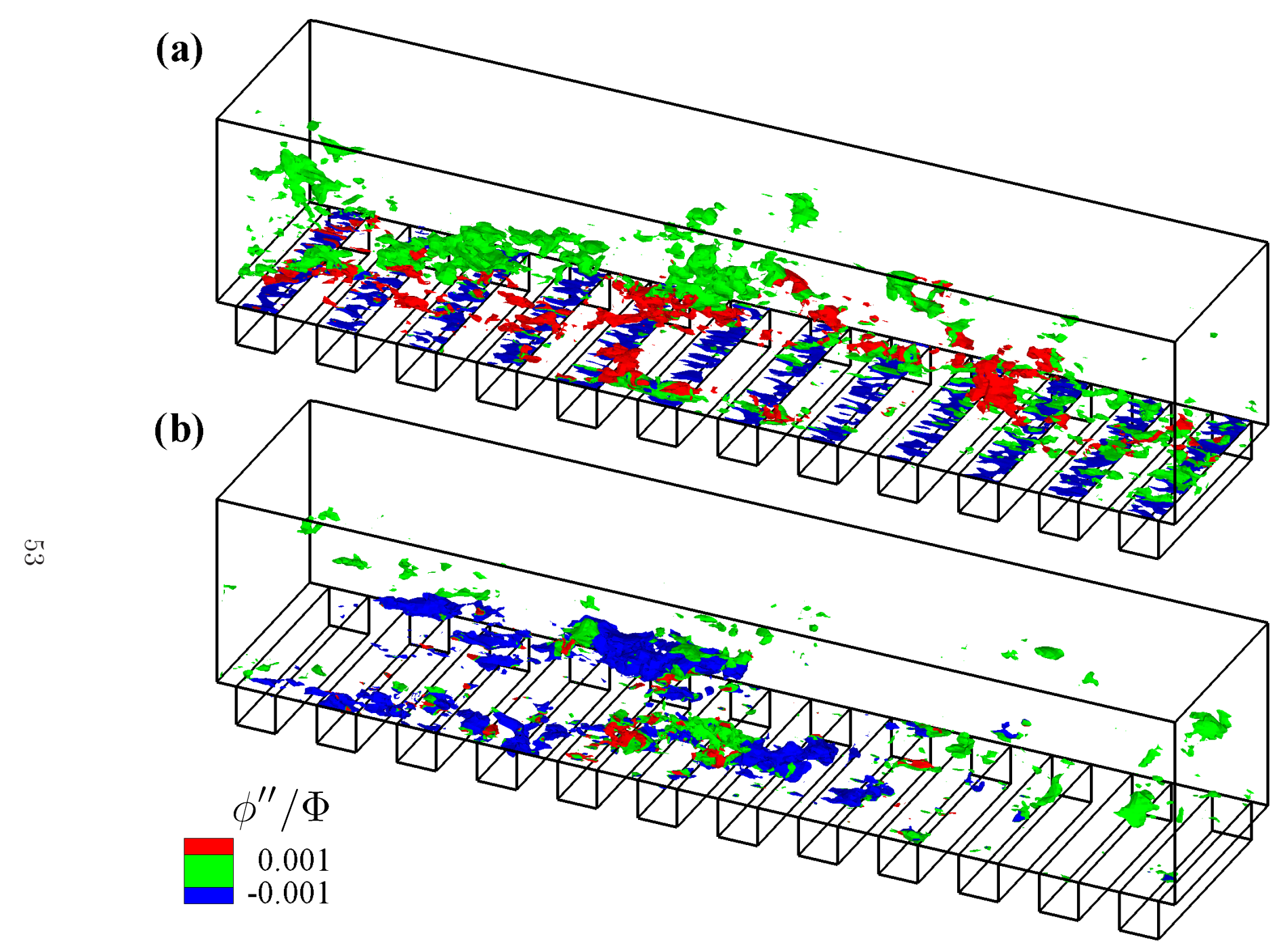

Figure 18: Isosurface of streamwise fluctuating velocity $u^{\prime \prime}=:$ (a). $-0.25 \mathrm{U}$ and (b). $0.25 \mathrm{U}$. Also shown are the contours of fluctuating pollutant concentration $\phi^{\prime \prime} / \Phi$. 


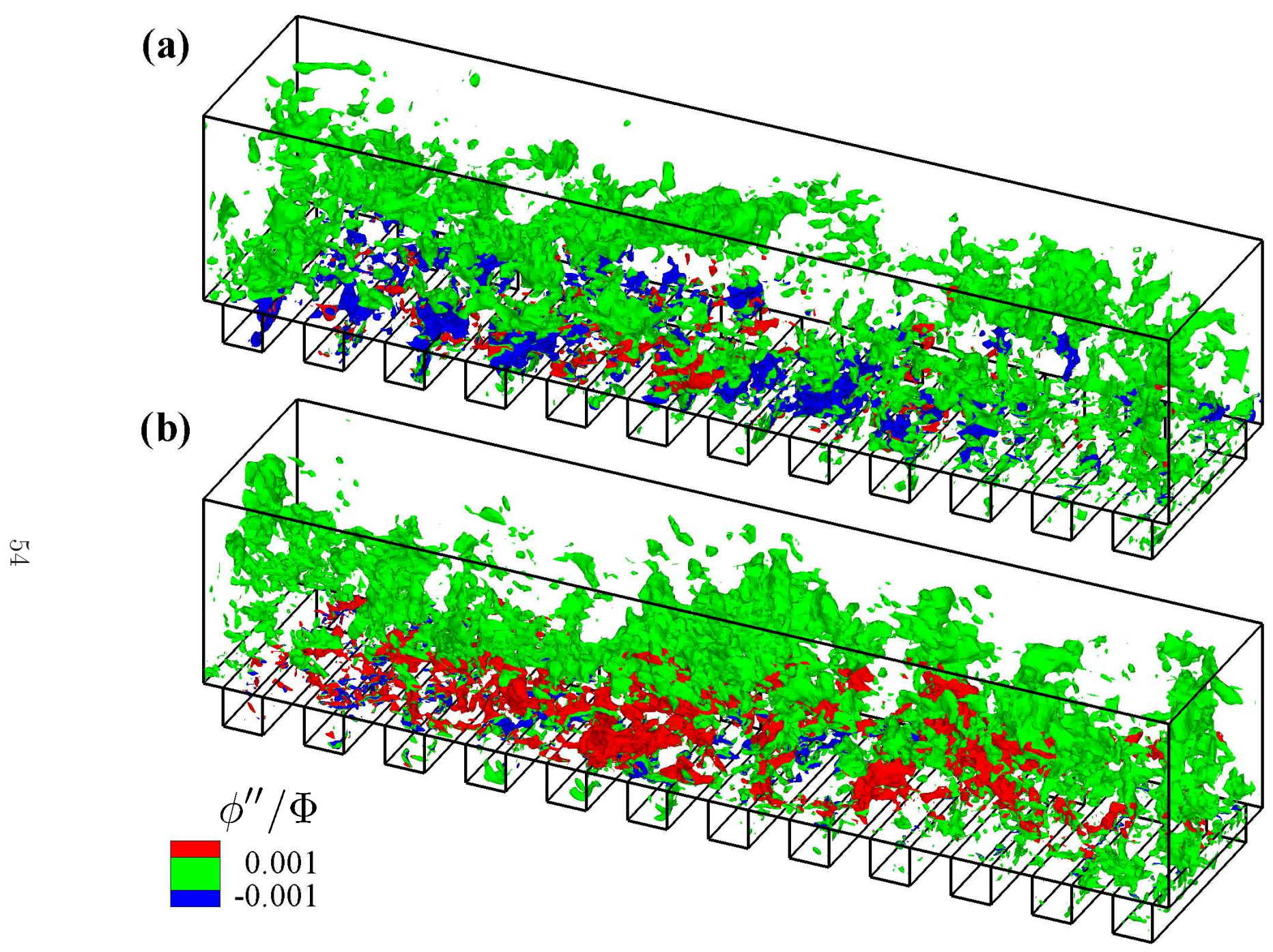

Figure 19: Isosurface of vertical fluctuating velocity $w^{\prime \prime}=:$ (a). $-0.1 \mathrm{U}$ and (b). 0.1U. Also shown are the contours of fluctuating pollutant concentration $\phi^{\prime \prime} / \Phi$. 